\title{
Copyright
}

by

Gregory Charles Wells

2005 
The Dissertation Committee for Gregory Charles Wells Certifies that this is the approved version of the following dissertation:

\section{MAKING ROOM FOR DADDIES: MALE COUPLES AND THEIR ADOPTED CHILDREN}

\section{Committee:}

Deborah J. Tharinger, Supervisor

Margaret Semrud-Clikeman

Diane L. Schallert

Laura Lein

Ruth McRoy 


\title{
MAKING ROOM FOR DADDIES: \\ MALE COUPLES AND THEIR ADOPTED CHILDREN
}

by

Gregory Charles Wells, B.A.; M.A.

\author{
Dissertation \\ Presented to the Faculty of the Graduate School of \\ The University of Texas at Austin \\ in Partial Fulfillment \\ of the Requirements \\ for the Degree of
}

Doctor of Philosophy

The University of Texas at Austin

August, 2005 


\section{Dedication}

Dedicated to John Fernandez, with love; to all the men who so generously shared their stories; and to all of my family and friends who supported me throughout this endeavor. 


\section{Acknowledgements}

The completion of this dissertation could not have been possible without the continued support and guidance provided by Deborah Tharinger (you are a mentor and a friend); the amazing men and their families who participated in this study (each one of you touched my life in a profound way); and to the Yancy family for always providing a

place to work and a place to stay on my many trips to Austin (I can't thank you enough). Finally, to my parents and my grandmother for their support and patience, all the while asking "are you finished with your paper yet?" 


\title{
Making Room for Daddies: Male Couples and Their Adopted Children
}

Publication No.

\author{
Gregory Charles Wells, Ph.D. \\ The University of Texas at Austin, 2005
}

Supervisor: Deborah Tharinger

Despite the increased visibility of gay and lesbian parents, absent from the literature is theory concerning how or why gay men decide to become fathers and how these families navigate the unique challenge of defining their families within a context of pervasive heterosexism and antigay prejudice. The current study utilized a grounded theory approach to aid in the development of a theory of gay male-headed family development. Questions considered included: Who are these men and how do they go about forming their families? What challenges do these families face in their daily lives and from whom or what do they seek support? Finally, what are the experiences of these families as they interact with such contextual forces as schools, communities, biological families, and chosen families? Results indicate that this new generation of gay fathers exhibit great strength and resiliency in constructing and raising their families. These men are themselves transformed by the act of fathering while at the same time acting as forces of change to transform the very idea of fatherhood in American culture. 


\section{Table of Contents}

List of Figures .............................................................................. $\mathrm{X}$

CHAPTER $1+1$

Introduction................................................................................ 1

$\begin{array}{lll}\text { CHAPTER } 2 & 5\end{array}$

Review of the Literature ........................................................................... 5

Fatherhood .................................................................................. 5

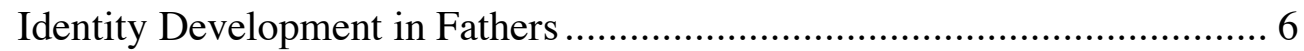

Primary Caregiving Fathers .......................................................... 7

Father Involvement................................................................... 9

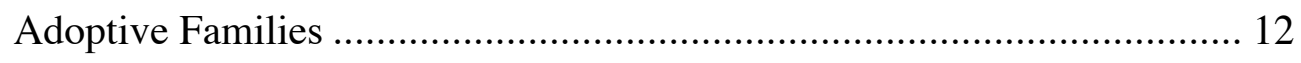

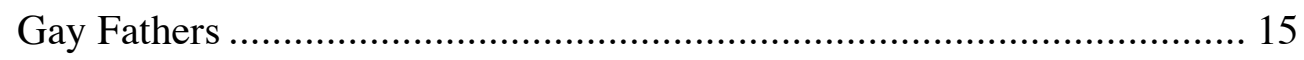

Foster and Adoptive Gay Fathers .............................................. 17

$\begin{array}{lr}\text { CHAPTER } 3 & \mathbf{2 0}\end{array}$

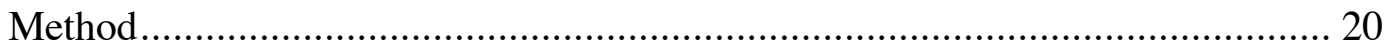

Qualitative Research and Grounded Theory ....................................... 20

Role of the Researcher........................................................................ 22

Recruitment Procedures ................................................................ 24

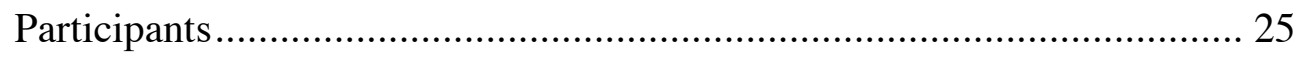

Table 1 Demographic Characteristics of Participants ................................ 26

Table 2 Demographic Characteristics of Children ................................... 26

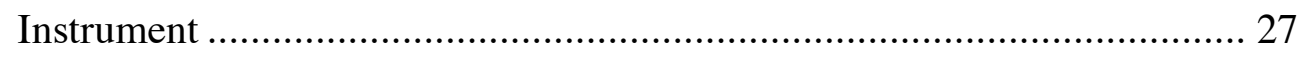

Data Collection Strategies.......................................................... 27

Analysis Procedures .................................................................. 28

Reliability and Validity .......................................................... 30

Ethical Considerations ............................................................... 31 


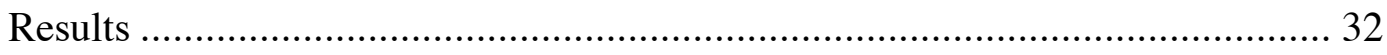

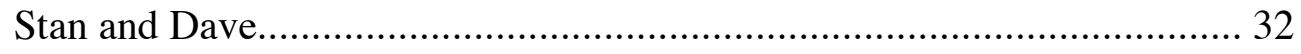

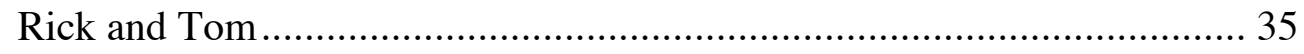

Categories and Related Concepts ......................................................... 37

Table 3 Forging New Ground ................................................................. 38

Forging New Ground - Multi-Faceted Identities ............................... 38

Gay Men Can't Have Babies!...................................................... 38

Two Men and a Baby? .......................................................... 42

Uncharted Territory - Rules and Roles.................................. 45

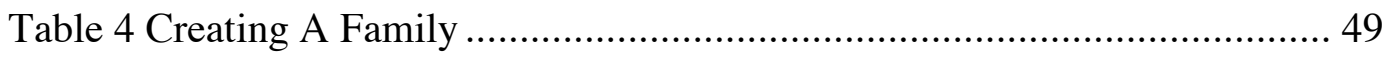

Creating A Family ...................................................................... 49

Families of the $21^{\text {st }}$ Century............................................... 49

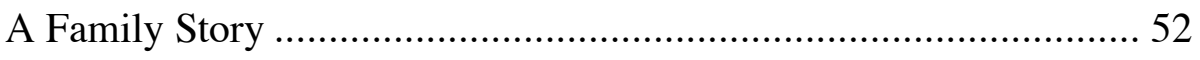

Family, Community \& Support Systems ................................... 59

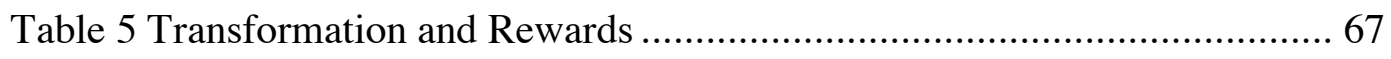

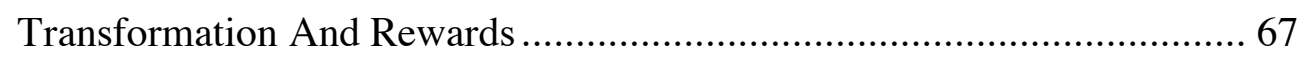

Personal Growth and Challenges............................................ 67

Adaptive Responses to Social Forces ......................................... 71

Visibility and Social Activism................................................. 76

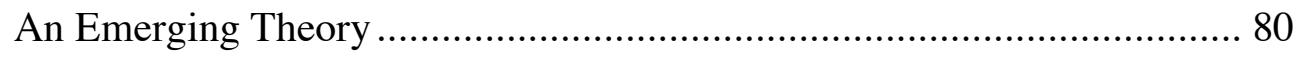

$\begin{array}{lr}\text { CHAPTER } 5 & 82\end{array}$

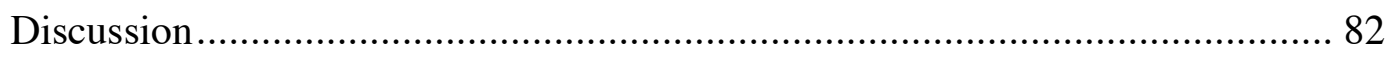

Model of Gay Father Development................................................... 84

Negative Socio-cultural Messages ......................................... 85

Multi-faceted Identities ...................................................... 87

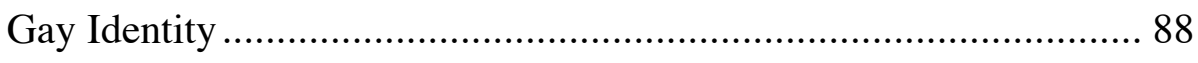

Man Identity …............................................................. 88

viii 


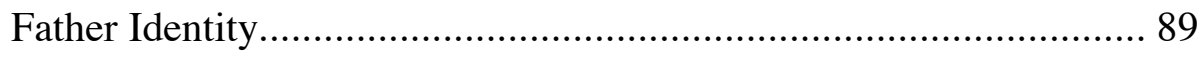

The Whole is Greater than the Sum ............................................ 90

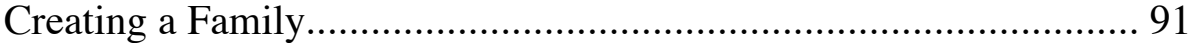

Family Development................................................................ 93

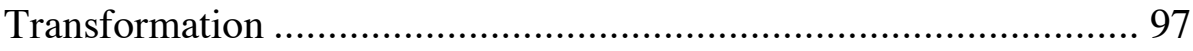

Positive Socio-Cultural Influences .............................................101

Research Findings with Similar Populations...............................103

Implications for Future Research.............................................105

Limitations of the Current Study .............................................107

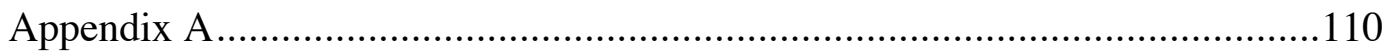

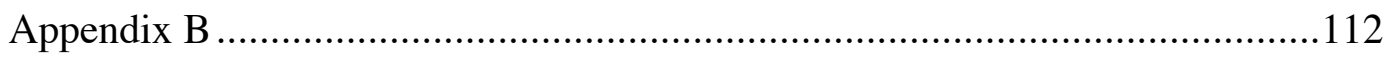

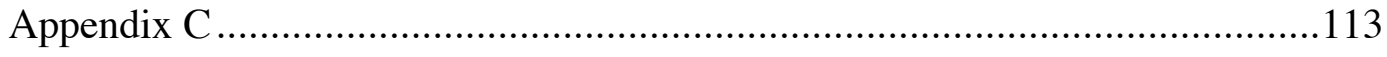

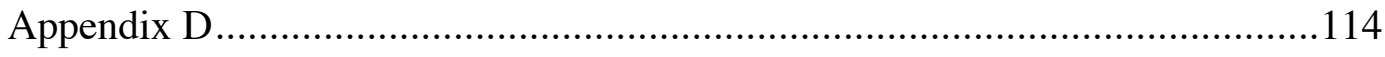

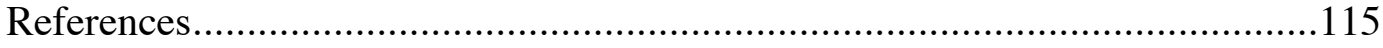

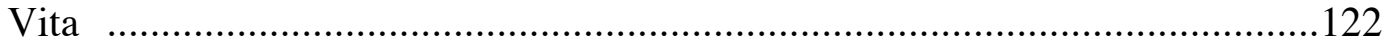




\section{List of Figures}

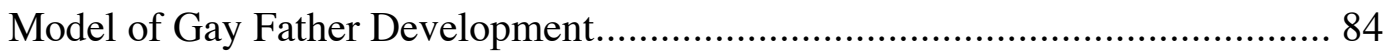




\section{CHAPTER 1}

\section{Introduction}

It is estimated that, in the United States, there are between 3 and 5 million lesbians and gay men who have parented more than 8 million children (Rothblum \& Cole, 1989; Harry, 1990; Patterson, 1998). According to the 2000 Census, of the more than 600,000 gay couples living together in the U.S., about 60,000 male couples and nearly 96,000 female couples have at least one child under 18 living at home (Smith \& Gates, 2001). These figures are merely estimates and it is impossible to determine the exact number of lesbian and gay parents or their children. The most striking feature of these families is not merely the number in existence, but the heterogeneity of such

families (Patterson \& Chan, 1996). Some lesbians and gay men have children from previous heterosexual marriages while others have children within committed same-sex relationships. Some lesbians choose donor insemination and some gay men opt for surrogate mothers. Still others serve as foster moms and dads. The current study focuses on the relatively new phenomenon of male couples who start their families through the process of adoption.

Gay men and lesbians have likely been parenting throughout the ages. However, this seemingly unique family structure has only recently come to public awareness. The 1990's saw a surge of interest in families headed by lesbians and gay men prompting some to label the phenomenon the "Gay-by" boom, although lesbian headed families far outnumbered gay male headed families (Stacey, 1998). Prior to increased media attention on such families, little was known about who they were and what they were like. Despite an increased interest in lesbian and gay headed families, only recently have 
researchers begun to empirically examine factors associated with this population. Most studies have focused on outcome variables concerning the children of lesbian parents (Patterson, 1995; Patterson \& Chan, 1999). Much of the research was prompted by the need to provide evidence to counteract claims that it is necessary for children to have a mother and a father in the home. Critics of such families argue that having two parents of the same sex is damaging to a child's development. Not surprisingly, such studies have shown that these children are virtually indistinguishable from the children of heterosexual parents. In fact, it could be argued that findings of "normalcy" in children of same-sex parents might indicate highly developed coping mechanisms and high resiliency.

Despite evidence that children develop as expected and even thrive in gay and lesbian families, many courts are still unwilling to award custody to a lesbian or gay adult (Flaks, Ficher, Masterpasqua, \& Joseph, 1995). Many lesbians who were previously married have been denied custody of their biological children because their ex-spouses and the courts learned of their sexual orientation (Achtenberg, 1990). Even if these mothers are granted joint custody it is often with the stipulation that their same-sex spouses must never be in the house with the children. The willingness of courts to make such rulings provides ample evidence that heterosexuality is still the norm to which all families are compared.

A more recent phenomenon is that of gay male couples choosing to adopt children and start families of their own. Very few studies have focused exclusively on gay men and their children. The majority of existing studies have used samples of men who have children from previous heterosexual marriages (Bozett, 1989). Data from this research suggest that these men are concerned with issues of "coming out" or openly discussing their sexual orientation with their children. Likewise, many of these men are 
simultaneously attempting to integrate an often newly discovered gay identity with their existing identity as fathers; a seemingly incongruous task for many men.

Despite the persistence of prejudicial attitudes and rulings toward gay and lesbian families, same-sex couples are finding many different ways to start families. Currently, the majority of male couples who have adopted tend to live in urban areas with somewhat more lenient and tolerant attitudes toward lesbians and gays. Some cities and counties (e.g., Austin, Texas and Travis County; San Francisco County and the Bay Area) and states (California, Oregon, Massachusetts, and New Jersey) are known for their willingness to grant adoptions to same-sex couples. Also, many couples pursue adoption by listing only one person as the parent, thus circumventing the need to come out to adoption agencies or judges.

Almost no studies have focused specifically on gay men who choose to start families within the context of a gay identity and within a gay relationship. To date, only two studies could be identified in the literature that examined planned gay families. Both studies are unpublished doctoral dissertations, yet they represent pioneering work in this area. Sbordone (1993) compared gay fathers to gay men who were not fathers and McPherson (1993) compared gay male parents to heterosexual parents. Results of each of these studies will be discussed in a later section. While families headed by gay men are likely to share many experiences with lesbian families as well as with heterosexual adoptive families, they are also likely to face challenges specifically related to their unique family constellation.

Due in large part to the need to prove the "worthiness" of lesbian and gay people to have children, much of the existing research has been quantitative in nature. This research has tended to focus on the sexual orientation and gender identity development of the children as well as their levels of stress and self esteem. Many researchers have 
suggested the need to examine additional characteristics of lesbian and gay families including dyadic adjustment and family process variables (Bozett, 1989; Patterson \& Chan, 1996, 1999).

Absent from the literature is theory concerning how or why gay men decide to become fathers and how these families navigate the unique challenge of defining their families within a context of pervasive heterosexism and antigay/antilesbian prejudice. The current study was based on a grounded theory approach with the aim of generating a knowledge base to aid in the development of a theory of gay male-headed family development. The goal was to provide answers to such questions as: Who are these men and how do they go about forming their families? What challenges do these men and their children face in their daily lives and from whom or what do they seek support? Does the identity development of gay fathers differ from that of non-gay fathers? Finally, what are the experiences of these families as they interact with such contextual forces as schools, communities, biological families, and chosen families? Analysis of the data collected provided rich insight into the lives of these unique families and aides in the construction of a theoretical framework that accurately reflects the lives of these men and their children. 


\section{CHAPTER 2}

\section{Review of the Literature}

This section provides a review of the social science literature on heterosexual

fathers and gay fathers, beginning with a discussion of fatherhood identity development in heterosexual men. Findings from research with primary caregiving fathers and the implications of these findings for research with gay fathers are then examined. Following this is a broad overview of the vast literature on adoptive families. Next, the limited available literature on gay men who became fathers while in heterosexual marriages is summarized. Finally, knowledge about foster and adoptive gay fathers and the need for additional research in this area is discussed.

\section{FATHERHOOD}

Historically, fatherhood has been discussed as a crisis in men's lives. Fears associated with an impending birth, greater financial responsibility, and issues associated with being a "good" father were assumed to represent a developmental crisis for new fathers. Current views conceptualize fatherhood as a developmental transition in the lives of men who choose to parent (Cowan, 1988). While the possibility for crisis exists, fatherhood also represents an exciting opportunity for men to expand their self identities through growth and exploration. Other researchers suggest that fatherhood is both a crisis and an opportunity (Osofsky, 1982). While literature on heterosexual fathers exists addressing these issues, researchers have yet to examine the effect of fatherhood on the lives and identities of gay men.

Comparisons of mothers' and fathers' transition to parenthood indicate that although there seem to be few differences in their reactions to the transition, not 
surprisingly, mothers are often more affected (Roopnarine \& Miller, 1985). Earlier research indicated that both mothers and fathers experienced extreme difficulty in adjusting to parenthood with each reporting chronic distress, loss of social contacts, and difficulty in providing continuous and prolonged infant care (LeMasters, 1957). Later research, however, failed to indicate that the transition to parenthood represented a severe crisis for either parent (Hobbs, 1965). Like other life events, the transition to parenthood came to be described as a normative developmental event that involved some transitional difficulties (Russell, 1974).

Other researchers have suggested that a sense of being a father occurs at different times for different fathers, which they refer to as the "fatherhood click" (Daniels \& Weingarten, 1982). They further assert that the experiential aspect of becoming a father occurs at a time that is distinct from the actual moment of birth of the child. For most men in their study, being a father meant, above all else, being a good provider. Most of the fathers also mentioned that they valued their relationships with their children as well and indicated a desire for involvement in the daily care of their children. As with mothers, the sense of knowing how to parent a child had to evolve, feelings of competence had to be learned, and fathers had to gain experience in order to be confident in their parenting skills. Similarly, Miller and Sollie (1980) described the transition to parenthood as a phase or span of time: "parental roles are acquired abruptly with the birth of a child, but there is also a more gradual transition into the skills and routines of parenting."

\section{IDENTITY DEVELOPMENT IN FATHERS}

There is a wealth of literature devoted to the general concept of identity development (Erikson, 1968; Waterman, 1992; Marcia, 1980), but relatively little devoted specifically to the identity development of men as fathers. Becoming a father 
may require some men to examine their deeply held beliefs regarding the self, while for others it may be a fairly easy process. At the very least, fatherhood likely requires "some integration of 'father' with already-established aspects of one's self-concept" (Cowan, 1988, p. 24).

Several researchers have considered the unique process of gay identity development (Cass, 1984; Troiden, 1989), but no research has examined the intersection of gay identity development and father identity development. If the development of an integrated gay identity represents a significant challenge for gay men, how does the development and integration of the additional father identity fit in? Until very recently, the acceptance and integration of a gay identity often precluded the possibility of fatherhood. Indeed, society and many gay men themselves believed that parenthood was the exclusive domain of heterosexuals, making gay fatherhood exotic or inconceivable (Patterson \& Chan, 1996). Thus, the identity development process for gay fathers continues to be an area ripe for investigation.

\section{Primary Caregiving Fathers}

Recent decades have seen a sharp increase in research devoted to fatherhood. Researchers have focused on the role of fathers in the family (Lamb, 1986), primary caregiving fathers (Radin, 1994), and the developmental process for men who become fathers (Cowan, 1988). Results of individual studies have varied, but most indicate that couples' decisions regarding parenting roles and responsibilities are influenced by several factors and result in considerable variation in how these roles are performed. Couples may decide prior to the birth that the father will be involved in a primary caregiving role, or that the role may be necessitated by the unemployment of the father and the resulting reliance on the mother's income. Some couples may also place greater value on the mother's career and support a focus on her continued employment while the father adapts 
his job to fit with his child care responsibilities. A sample of these many possibilities and their implications for fathers is considered in this section.

Findings from one study suggest that fathers in primary caregiving roles were influenced to take on such roles either by a desire to repeat their own experiences with their fathers or by a desire to remake these past experiences (Pruett, 1989). The researcher also suggests that these men appear to marry independent women who were somehow less inclined toward a nurturing family role. Similarly, Radin and her colleagues (Radin, 1988; Radin \& Russell, 1983; Russell \& Radin, 1983) hypothesized a link between fathers' experiences with their own fathers and their propensity toward a nontraditional father role. Specifically, the researchers suggested that primary caregiving men were more likely to have fathers who were less available, less loving, and less powerful in the decision making of the family. However, the researchers found little support for a connection between father's role in child rearing and his view of his own father. Instead, father participation in child rearing appeared to be influenced by the fact that the mothers of both parents had worked outside the home before they were 10 years old. To date, no research has examined factors that influence gay fathers decisions regarding which parent works outside the home and which is the primary caregiver.

In their qualitative study of primary caregiving fathers, Lutwin and Siperstein (1985) identified several important characteristics of primary caregiving fathers and the adjustment of the fathers to this reversal of roles. The authors found that fathers who chose to fulfill the primary parent role were happier with the arrangement than fathers who were thrust into the role involuntarily. The fathers in the study indicated a need for support from extended family, friends, and neighbors that was intensified by a lack of resources within the community. In their discussion of fathers' adjustment to their new role, the authors identified three major tasks confronting primary caregiving fathers. 
These tasks may also be conceived as developmental challenges and include: 1) domestic tasks or learning to run the household and care for the children on a daily basis; 2) personal tasks, including dealing with role strain and resolving traditional myths concerning women's work and men's work; and 3) environmental tasks such as dealing with isolation and boredom and confronting social institutions that do not accept fathers in nontraditional roles. These findings suggest that primary caregiving fathers, while capable and competent in their nontraditional role, face unique stressors as they navigate heretofore uncharted territory.

\section{FATHER INVOLVEMENT}

Lamb and his colleagues (Lamb, Pleck, Charnov, \& Levine, 1987; Pleck, Lamb, \& Levine, 1986) propose that level of paternal involvement is influenced by four factors: motivation, skills and self-confidence, social supports, and institutional factors or practices. They hypothesize that motivation is influenced by 1) the father's developmental history such as own father's involvement (discussed previously), age of the father, marital history, and socialization; 2) personality characteristics, including gender-role orientation, self-esteem, and self-identity; and 3) beliefs concerning the role of fathers in child development.

As discussed previously, research on transitions to parenthood suggests that developing the skills and self-confidence to parent develop gradually through repeated interactions with the child. Research also indicates that fathers' level of involvement with their children is associated with their self-perceived competence in interacting with children (Baruch \& Barnett, 1986; McHale \& Huston, 1984). Level of paternal involvement also appears to be predicted by fathers' holding positive beliefs about men's competence with children (Russell, 1986). 
In their discussion of social supports and stresses, Lamb, et al. (1987; Pleck et al., 1986) focus primarily on maternal employment and marital dynamics as they influence level of paternal involvement. For example, fathers tend to be more involved, although rarely as primary caretakers, when mothers are employed. Higher levels of paternal involvement also appear to be associated with good marital relationships. Finally, research suggests that men's social networks rarely support greater involvement in child care (Lein, 1979) and may, in fact, react to greater involvement with hostility (Hwang, Elden, \& Frannson, 1984; Russell, 1986). Women's social networks, on the other hand, tend to support and often expect a mother to be highly involved in the daily care of her children.

Finally, the workplace is most often identified as the institution with the largest impact on fathers' involvement. Like their wives, working fathers experience significant stress in combining work and family roles and many report that they desire work policies to reduce this stress (Pleck, 1997). However, men's jobs tend to be less flexible and less willing to allow fathers time off to tend to children's illnesses or problems. Because this has typically been the domain of women, employers have created and maintained a sense that a father's work takes precedent over his need or desire to parent (Pleck, 1997). Research on dual earner families indicates that women often sacrifice career aspirations or advancement for increased involvement with their children (Rapoport \& Rapoport, 1976; Gilbert, 1988).

Only one study was identified which specifically examined level of involvement and role orientation in same-sex parents. In her research with lesbian parents, Patterson (1995) found that these couples reported sharing household tasks and family decision making equally, but biological mothers reported greater involvement in child care, and nonbiological mothers reported more time devoted to paid employment. These findings 
suggest that lesbian parents, like heterosexual parents, specialized with regard to their involvement in child care versus paid work. However, further analysis of the data indicate that division of the labor involved in child care was more pronounced among heterosexual than among lesbian couples (Patterson, 1995).

It should be noted that there is no evidence to suggest that one sex is any more "naturally" nurturant than the other (Park \& Swain, 1976; Lamb, 1997). Some families make deliberate decisions about who will take a primary parent role based on a shared ideology and others are forced into such situations by financial and other extenuating circumstances. As with other areas in the lives of couples, child care responsibilities are continually negotiated (Cowan \& Cowan, 1987).

Little is known about how issues of child care and primary parenting are negotiated in gay male headed families. For gay men, gender role and sex role expectations do not clearly indicate which parent should be career focused and which parent should be child focused. How then do gay fathers navigate this social reality that women have always confronted? Are gay men more likely to employ egalitarian methods for balancing careers and child care? Do some gay fathers choose more nontraditional jobs? Do some tend to work at home? Studies have yet to include gay or lesbian families as part of their research and limited data exists in this area, especially concerning gay male parents. Implications of the answers to these questions have the potential to effect the way heterosexual parents negotiate the demands of work and the need to parent. Of equal interest to the current study is how adoption influences one parent to assume a primary parent role as opposed to the other parent. We will now consider some of the unique characteristics of adoptive parents and their children. 


\section{ADOPTIVE FAMILIES}

Adoptive parents differ from biological parents in several ways. First and foremost is their experience of becoming parents. Biological parents may become parents with little or no planning or after many years of preparation. In either case, biological parents can plan for and control the timing of the child's arrival. Adoptive parents often spend a considerable amount of time waiting for a child whose arrival is something over which they have little if any control (Roopnarine \& Miller, 1985). Even when prospective adoptive parents have endured long waiting periods, the actual arrival of the child may occur quite abruptly. Finally, Roopnarine and Miller (1985) suggest that a major defining characteristic of adoptive parents is that they become parents socially and legally, but not biologically. It is unknown whether these factors are salient for all adoptive families. Regardless, they represent important nonnormative features that differentiate adoptive families from biological families.

Grotevant and Kohler (1999) discuss several processes important to adoptive families, including acknowledgment of difference, control, and coping with loss. The first construct applies primarily to family dynamic processes with the remaining two concerned with individual processes. The researchers further suggest that each of these issues must be considered within the context of the amount of openness in individual adoptions versus secrecy. It should be noted that all of the research on which the following discussion is based was conducted with heterosexual adoptive families and the relevance of the findings to lesbian and gay adoptive families is unknown.

Of significance to most contemporary adoptions is the issue of openness versus secrecy. With the sweeping changes in adoption practice since the 1970 s, some level of openness has become standard practice in many adoptions. Adoption professionals have pushed for options permitting contact and communication between birth parents and 
adoptive parents and adopted children in hopes of humanizing the adoption process for all parties involved.

Few studies have examined the effects of different levels of openness on adoptive families. In one study (Grotevant \& McRoy, 1998), three levels of openness were explored: confidential adoptions in which no information was exchanged and there was no contact between birth parent(s) and adoptive families; mediated adoption, in which limited, nonidentifying information is exchanged between birth parent(s) and adoptive families (usually through an agency); and open adoptions which are typified by an ongoing contact between birth parent(s) and adoptive families with full exchange of identifying information. In discussing their findings, the researchers stress the ongoing nature of the adoption process as opposed to being a discrete event that ends with the signing of papers or the arrival of the infant or child. Other relevant findings from the study are that in fully disclosed adoptions, parents demonstrate higher levels of empathy concerning the adoption, they talk more openly with their children, and have less fears about birth mothers attempting to reclaim their children than parents in confidential adoptions (Grotevant \& McRoy, 1998).

Another area of research has focused on the need for adoptive parents and families to acknowledge the fact that they are different from the majority of other families. It has been suggested that couples who adopt because of infertility suffer from a role disadvantage because they become parents in a non-normative manner (Kirk, 1981). Kirk (1981) suggested that it was necessary and healthy for adoptive families to acknowledge their difference from biological families. This suggestion was a reaction to the practice of "pretending" to be a biologically related family and keeping the adoption from the children. Other researchers cautioned that too much of a focus on difference could be detrimental to the parent child relationship (Brodzinsky, 1987). While it is 
possible that heterosexual adoptive couples may experience some challenges in coping with this difference, quite the opposite may be true for gay men. Typically, gay men don't have the option of "pretending" to be biological parents. While it is certainly possible for one man to be the biological father, the other can not pretend to be the mother. Instead of adapting to the loss of a previously taken for granted role, adoption represents a great new possibility for many gay fathers. Along with the challenge of adaptation to a new role, adoption holds the potential as an opportunity for growth and development in the lives of gay men. Again, such possibilities have only recently begun to be explored.

As mentioned above, heterosexual couples and many lesbian couples frequently arrive at the decision to adopt after several failed attempts at having biological children. Indeed, it is common practice for adoption counselors to suggest that potential adoptive parents mourn the loss of the (biological) children that they will never have. Thus, couples are faced with the dual task of dealing with symbolic loss of a child as well as a loss of control over their biological destiny. Grotevant and Kohler (1999) discuss the issues of control and loss separately, but for present purposes the discussion will be combined. While it is true that many parents arrive at the choice to adopt after many attempts at pregnancy, this can not be said for all adoptive parents. The process is potentially quite different for gay men. Typically, their biological functioning is not in question. Rather than suddenly being faced with infertility, gay men are fully aware of their reproductive limitations from the beginning. It is possible that the issues of control and loss might not be as salient for gay male adoptive couples as for heterosexual adoptive couples.

As suggested in the above discussion, there are likely to be many similarities in the experiences of heterosexual adoptive families and gay adoptive families. However, 
adoption research has yet to include same-sex parents and therefore the relevance of current findings to lesbian and gay adoptive families is unknown and caution in interpretation is warranted. Grotevant and Kohler's (1999) call for more process-oriented adoption research is relevant to all adoptive family constellations, but is particularly relevant to adoptive families headed by gay men as little research exists in this area. The proposed study will attempt to shed some light on possible similarities and differences between heterosexual adoptive families and adoptive families headed by male couples.

\section{GAY FATHERS}

Much of the past research on gay fathers has been concerned with men who were previously in heterosexual marriages and later came out or acknowledged their homosexual identity (Bozett, 1980; Skeen \& Robinson, 1984). As long as strong societal disapproval of lesbians and gays persists, many men who will later identify as gay will likely continue to marry. However, it is also possible that the momentous advances made by the lesbians, gays, and bisexuals in recent history have made it more likely that fewer people will feel forced to attempt a heterosexual lifestyle, though this possibility has yet to be researched. Therefore, the concept of same-sex couples having a family and all that was heretofore only available to heterosexual couples (e.g., children, grandchildren, social status) is an entirely new phenomenon in our culture. Granted, there have always been lesbian and gay parents, but the current social phenomenon of lesbian and gay families demanding recognition as a family unit is unprecedented.

The question often arises as to why gay men get married in the first place. Not surprisingly, they marry women for many of the same reasons that heterosexual men do. Bozett (1988) postulates that some gay men may be in love with a woman or they may strongly desire children and believe that it is necessary to marry in order to do so (Bozett, 1988). Other gay men are influenced by strong heterosexist societal attitudes and believe 
that it is impossible to find love and happiness with another man. These men marry in hopes this will rid them of their attraction to other men. Strong parental pressure and cultural norms may also influence some gay men to attempt heterosexual marriages.

In his research with gay fathers, Bozett $(1988,1989)$ found that a majority of heterosexually married gay men eventually divorced their wives (or vice versa) and began to live their lives within the context of a gay identity. The courts have historically awarded custody of children to mothers and many gay men did not have the option of raising their children. After the divorce, some men were forced to psychologically distance themselves from their children in order to keep their sexual orientation secret, for fear of stigmatizing their children or losing the love of their children (Miller, 1979). Also, not all gay men disclosed their sexual orientation to their wives prior to or following the divorce. Many were afraid their wives would deny them visitation rights if they found out their ex-husbands were gay. Consequently, these men were forced to hide their sexual orientation from their children as well. Such secrecy often had a negative impact not only on the father-child relationship, but also on the man's developing identity as well (Clark, 1977).

However, some gay men are awarded custody of their children following divorce. One study found that ten percent of gay fathers were custodial parents (Wyers, 1984). This figure approximates the national average of ten percent of children living in father headed single-parent households (Hanson, 1985). As with all custody cases, some exwives voluntarily relinquish custody and others are denied custody by the courts. It appears that gay fathers who are awarded custody of their children may be more likely to openly discuss their sexual orientation with their children. Furthermore, such fathers are more likely to disclose their sexual orientation to their children because it is an integral part of their developing identity as a gay man (Bozett, 1988). 
Much of the research presented above indicates that gay men who became fathers in the context of heterosexual marriages encountered unique challenges as they attempted to merge their identities as fathers with their newly forming identities as gay men. Much of the data on which the above research is based were collected in the late 1970s. While gay people continue to be a stigmatized and marginalized minority, the gay rights movement has made significant advances since the original data were collected. Many more lesbians and gay men are able to live their lives openly and are choosing to start families within the context of a committed same-sex partnership. Changes in societal attitudes and family law have also made foster parenting and adoption a new option for gay men who wish to have children. Research with these families holds the possibility of increasing our understanding of how families define themselves and how they adjust to challenges related to their family structure.

\section{FOSTER AND ADOPTIVE GAY FATHERS}

Foster and adoptive laws vary from state to state and from county to county. Currently, Florida is the only state that specifically outlaws adoption by gay or lesbian adults. Because of prejudicial practices in adoption agencies as well as in family courts, gay men who wanted to adopt often had to fight their way through the system (Ricketts, 1991). Gay men seeking to adopt through public adoption agencies were often only offered difficult to place children, including older children, children of mixed ethnicity, and children with severe illnesses or disabilities (Patterson \& Chan, 1997). As a result, many gay adoptive fathers were faced with additional challenges in starting their families. While such descriptive accounts exist concerning the paths to fatherhood for gay men, no research has addressed the transition to fatherhood among gay men.

Likewise, only two studies have focused on gay men who became fathers after self-identifying as gay. Both studies are from unpublished doctoral dissertations, and 
follow up studies have yet to be reported. Sbordone (1993) compared 78 gay men who had become fathers through adoption or through surrogacy with 83 gay men who were not fathers. The men were compared on measures of internalized homophobia, selfesteem and recollections of their families of origin. There were no differences between the two groups of men regarding relationships with their own parents however, gay men who were fathers did report higher self-esteem and fewer negative attitudes about homosexuality than did gay men who were not fathers.

Another interesting finding of Sbordone (1993) was that a majority of the gay men who were not fathers reported that they would like to someday parent a child. Given the finding that gay fathers had higher self-esteem and fewer negative attitudes about homosexuality, the researcher hypothesized that higher self-esteem among gay fathers might be a direct result of parenthood as opposed to a cause or simple correlate. Additional research in this area has yet to be reported.

McPherson (1993) compared 28 gay male parenting couples and 27 heterosexual parenting couples on measures of division of labor, satisfaction with division of labor, and satisfaction with couple relationships. Gay couples reported a more egalitarian distribution of responsibilities for home and child care than did heterosexual couples. Not surprisingly, gay couples also reported more satisfaction with division of labor than did heterosexual couples. Gay couples also reported higher levels of satisfaction with their couple relationships, particularly in the areas of cohesion and affective expression.

Of the two studies with male couples, neither examined factors associated with male couple's decision to adopt children and raise a family together as a couple. Due partly to the legal and social obstacles associated with same-sex parent adoption, male couples must engage in a deliberate and protracted process concerning the decision to adopt. In addition to the financial and legal obstacles shared by heterosexual adoptive 
parents, gay men face their own set of unique obstacles. Many spend a great deal of time considering such factors as how parenting will isolate them or their children from relatives, friends, community, and society in general, in addition to valid fears about exposure to prejudice and possible violence (Martin, 1993). As Patterson and Chan (1999) note, little is known concerning the determinants of parenting, especially among gay men.

\section{Summary and Statement of the Problem}

The psychological literature is severely lacking in current research on the experiences of gay men who choose to start families through adoption and within the context of an accepted gay identity and a committed relationship. In order to better understand the experiences of male couples who choose to adopt and to provide insight into the contextual meaning of their lives, qualitative designs that fully explore these men's lives and experiences from their perspectives are particularly timely. Through indepth interviews with men who have formed families through adoption and within the context of a committed relationship, findings from the current study will provide insight into

- the reasons why these men choose to start families through adoption.

- how male couples navigate the adoption process.

- how role division is decided in gay male families.

- the identity development of gay fathers.

- the varied experiences of gay fathers.

- the cultural context of gay fathers and their children. 


\section{CHAPTER 3}

\section{Method}

Prior to discussion of the current study, a brief overview of the methodology will be provided. Qualitative research methods and grounded theory and their application to the current study will first be discussed. Next, detailed information specific to the current study, such as setting, subjects, and data collection and analysis methods will be provided, followed by discussion of ethical issues.

\section{QUALITATIVE RESEARCH AND GROUNDED THEORY}

For the current exploratory study on gay fathers and their adopted children, qualitative research methods emerge as the method of choice for investigating this new social phenomenon. When little is known about a social phenomenon or when the researcher's aim is to examine non-dominant cultures or subcultures within the larger society, qualitative methodology offers several advantages over quantitative methodology. For example, the researcher may take a much more active role in the collection of data, and while remaining keenly aware of personal beliefs and assumptions about the subjects under study, the researcher's goal in to refrain from imposing his or her assumptions on research participants. The goal is to allow the research participants to speak about their experiences and "give voice" to a heretofore-unheard experience.

One characteristic of qualitative research is that it yields description of the phenomenon one is investigating. The descriptive material then yields concepts by which people understand their world. These concepts are categorized and used to generate hypotheses to be examined quantitatively. In most cases, quantitative research aims to confirm hypotheses developed prior to actual data collection and analysis. The data of 
qualitative research are non-numerical texts composed of the participants' own subjective definition of their experience as reflected in their narratives and discussions of a social phenomenon. Data analysis involves the interpretation and explication of the meanings and structures implicit in the texts. In qualitative research, theory is developed in the process of data analysis. Ongoing theoretical development proceeds concurrently with both data collection and analysis.

According to Rubin and Rubin (1995), qualitative research is particularly useful in examining cultures about which little is known, or phenomena that lack a theoretical framework. They assert that the paradigm allows the researcher to collect an extremely detailed description of the world of the participants who experience the phenomenon being studied. The first step in qualitative research involves the collection of texts produced through interviews with members of a culture as they talk about and reflect on a particular phenomenon. The participants' own biases and descriptions of the phenomenon are documented in these texts, or transcripts that comprise the data for later analysis. One step of the analysis procedure involves using the researcher's own subjectivity in a disciplined way to enter into and interpret the subjects' world vis-a-vis the transcripts. Data analysis also leads to the identification of cultural themes, or concepts and categories by which subjects make meaning of their world and their experiences. Finally, qualitative research leads to the development of grounded theory. Strauss and Corbin (1990) define a grounded theory as

one that is inductively derived from the study of the phenomenon it represents. That is, it is discovered, developed, and provisionally verified through systematic data collection and analysis pertaining to that phenomenon... One does not begin with a theory, then prove it. Rather, one begins with an area of study and what is relevant to that area is allowed to emerge (p. 23).

Qualitative research is often used to generate hypotheses that may then be examined quantitatively. 
For the present study, the phenomenon of interest was the experiences of male couples who have adopted one or more children. Related to this central phenomenon are the related phenomena of gay father identity development and the social and cultural context within which gay fathers and their adopted children live. Rather than seeking to prove a theory of adoption by gay men or of the identity development of gay men, the goal of the current study was to observe, primarily through interviews, the experiences of adoptive male couples so that a theory of gay male parenting by adoption could be derived from the data.

\section{ROLE OF THE RESEARCHER}

Quantitative research designs traditionally employ surveys or psychometric tests to collect data. With grounded theory research, however, the investigator is the principal instrument used for data collection. Along with observations, the investigator conducts interviews that are recorded, transcribed, analyzed and interpreted. On occasion, grounded theory research may be combined with quantitative measures, but the investigator is generally the primary data collection instrument.

Quantitative theory is based on the idea of the objective researcher and generally gives little credence to the personal beliefs, biases, histories, and values of the researchers employing these methods. These researcher variables and the influence they exert on data interpretation are often overlooked in quantitative designs. Grounded theory, however, makes use of the ideological presence of the researcher through "theoretical sensitivity" (Strauss \& Corbin, 1990). Theoretical sensitivity refers to the researcher's ability to effectively interpret the data due to prior knowledge (i.e., life and/or professional experience) in the area under investigation. While prior knowledge in the area under study along with knowledge of existing theory may interfere with emerging theory, theoretical sensitivity can also aid the researcher by enabling him/her to ask necessary 
follow-up questions, to efficiently categorize concepts, and to appreciate the context within which the data are embedded.

One of the unique characteristics of grounded theory is that values and biases inherent in research are recognized and utilized. Rather than attempting to avoid or discount personal values and biases, the researcher attempts to remain keenly aware of these influences and how they may add to or detract from the phenomenon under study. Strauss and Corbin (1990) view the histories and experiences of the researcher as both a blessing and a curse. When unrecognized, the values of the researcher can negatively influence a study, but when confronted throughout the study they can encourage the theoretical sensitivity needed to efficiently collect and analyze data.

To illustrate the awareness of values as they relate to the current proposed study, I believe that many types of family structures have value and that none is more "right" than another. Families may be comprised of adult members of the opposite sex, of the same sex, or of any variety of gender or sex. Likewise, I do not believe it is necessary to have two parents of the opposite sex in order to provide a nurturing home for a child. These values and beliefs certainly influenced the manner in which I constructed this study, how I conducted the interviews, and how I interpreted the data. Rather than rendering my study invalid or "unscientific", acknowledgment of my values encouraged me to remain aware of their influence and allowed me to make efforts to limit their influence when necessary.

To summarize, I served as the primary data collection instrument in the current study. Both data collection and data analysis were my responsibility. Prior to beginning the study, I endeavored to become fully aware of my values and ideas as they related to the population under investigation. Rather than viewing this as problematic in terms of researcher bias, my values were acknowledged and embraced. While they certainly 
influenced the study, they were also an important source of information and theoretical sensitivity. The following sections will more fully describe the specifics of grounded theory research as they relate to the current study.

\section{RECRUitMent PRoCedures}

The men in this study were recruited through personal contacts and word of mouth using a snowball procedure. A physician who is a member of a gay and lesbian physicians group in the San Francisco Bay Area referred the first couple. The first couple then referred two additional couples, and so on up to six couples. The sixth couple then referred the researcher to an on-line gay father discussion group. The final four couples were recruited via a posting to the "DadMail" discussion group. Interviews were conducted between 2001 and 2004.

Participation in the study was limited to male couples residing in the San Francisco Bay Area. By both reducing and better elucidating geographic and social/contextual factors, it was hoped that the results obtained would provide valuable insight into a new social phenomenon. While such homogeneity may limit the generalizability of the findings, given the lack of research with this population I felt it was necessary to reduce as many extraneous variables as possible. In addition, participation was further limited to fathers that had adopted as couples and whose children had been adopted within the previous three years. Men who had adopted as singles parents or who had acquired children through other means (e.g. surrogacy or coparenting arrangements) were excluded from participation. Such restrictions were placed on participation in order to better interpret the interview data. Because adoption by gay male couples is still a rather new social phenomenon and because few researchers have studied this population exclusively, I felt it was necessary to reduce as much participant variation as possible. 


\section{PARTICIPANTS}

The participants in this study were comprised of 10 gay male couples living in the San Francisco Bay Area. Nine of the interviews were conducted in participants' homes and one interview was conducted in a meeting room of an area hotel. Each interview lasted 1.5-3 hours.

The ages of the men ranged from 31-50, with a median age of 39 . The ethnic make-up of the group was predominantly Caucasian (80\%), with 5\% Filipino, 10\% Latino, and 5\% Black. Fathers' levels of education ranged from high school graduate to holding a graduate degree. The majority of household incomes fell at or above $\$ 100,000$ per year.

The men had either one or two children, with a total of 13 children for the sample. The children ranged in age from 8 months to 5.5 years of age, with an average age of 2.18 years. Table 1 summarizes demographic data for the twenty gay fathers (10 couples). See Table 2 for demographic data on the children. 
Table 1 Demographic Characteristics of Participants

\begin{tabular}{|c|c|c|}
\hline & Number & Percentage \\
\hline Ethnicity & 2 & $10 \%$ \\
\hline Latino* $^{*}$ & 1 & 5 \\
\hline Black & $3 * *$ & 15 \\
\hline Jewish* & 1 & 5 \\
\hline Filipino & $16^{* *}$ & 80 \\
\hline Caucasian & 1 & 5 \\
\hline Highest Education Level & 9 & 45 \\
\hline High School Graduate & 10 & 50 \\
\hline College Degree & & 20 \\
\hline Doctoral Degree & 2 & 80 \\
\hline Household Income*** & 8 & 70 \\
\hline $75-100 \mathrm{k}$ & & 30 \\
\hline$>100 \mathrm{k}$ & 7 & \\
\hline Own vs. Rent $* * *$ & 3 & 70 \\
\hline Own & & 30 \\
\hline Rent & 7 & 60 \\
\hline Number of Children*** & 3 & 40 \\
\hline One child & 6 & \\
\hline Two children & 4 & \\
\hline Participate in Daycare*** & & \\
\hline Yes & & \\
\hline No & & \\
\hline Terms used are those used & & \\
\hline
\end{tabular}

* Terms used are those used by the participants.

** Some participants claimed more than one ethnicity (e.g. Caucasian \& Jewish)

*** Percentages based on couple responses (i.e. 10 couples)

Table 2 Demographic Characteristics of Children

\begin{tabular}{|c|c|c|}
\hline & Number & Percentage* $^{*}$ \\
\hline Ethnicity & & 8 \\
\hline Latino/a & 1 & 8 \\
\hline Latino/a / Caucasian & 1 & 8 \\
\hline Black/Caucasian & 1 & 77 \\
\hline Caucasian & 10 & \\
\hline Gender & 2 & 15 \\
\hline Female & 11 & 85 \\
\hline Male & & \\
\hline
\end{tabular}

*Percentages are rounded up 


\section{INSTRUMENT}

As indicated earlier, the researcher served as the primary data collection instrument. Semi-structured interviews were conducted with adult male couples who had adopted at least one child. The first two interviews followed the questions included in Appendix A. However, as the data from the first interviews were analyzed and as future data were collected, research questions were modified as part of the grounded theory research process. As data were simultaneously collected and analyzed, concepts and categories emerged. Occasionally, emergent categories required further investigation and questions were added or deleted to investigate the category under question. The majority of interviews were based on the questions included in Appendix B.

\section{Data Collection Strategies}

Participants were interviewed following the format included in Appendices A and B. All interviews were taped and then transcribed. All participants completed brief demographic questionnaires (Appendix C) and signed consent forms (Appendix D).

To further provide an understanding of the cultural context of male couples and their adopted children, documents were collected from Bay Area agencies that provide services to Gay and Lesbian parents and prospective parents. These support services provide adoption information and counseling for current and future parents as well as networking opportunities and information on legal issues related to same-sex parent adoption. Cultural context was assessed in order to identify factors that influence the lives of male couples and their adopted children, such as systems of support as well as sources of discrimination and prejudice. 


\section{AnAlysis Procedures}

Data analysis procedures followed the methods advocated by Strauss and Corbin (1998) and Rubin and Rubin (1995) for the development of a grounded theory. As such, the texts were analyzed and emergent categories were constantly checked across transcripts. It is important to note that unlike many quantitative methods, qualitative analysis does not proceed in a sequential and linear manner. The very nature of the data collection and analysis process requires that categories be continually modified to reflect the evolving or emerging theory. The tenets of grounded theory dictate that analysis of data occurs simultaneously with data collection. Qualitative (non-quantified) data are collected through interviews, observations, reviews of documents, the internet, etc. and coded or organized into meaningful units.

Open coding involves the process of taking the transcribed interviews and breaking them down into discrete concepts. Concepts are derived from the interviewees' actual dialogue. These concepts form the basic unit of analysis in grounded theory. As additional interviews are conducted and analyzed, the investigator begins to observe similarities among concepts. Similar concepts are then grouped into categories and transcripts are re-coded to account for the newly emerging categories. At this point, the investigator begins to analyze at a higher more conceptual level. As this process is repeated, important categories emerge that are repeated across a majority of interviews. These concepts and categories are examined to elucidate their propertied and the range of variation among participants.

Following open coding, the investigator uses axial coding to identify the context of the categories and relationships that exist between categories. According to Strauss and Corbin (1998), the purpose of axial coding 
is to begin to begin the process of reassembling the data that were fractured during open coding...categories are related to their subcategories to form more precise and complete explanations about phenomena (p124).

At this point in the analysis process, the researcher is concerned with the context within which the phenomenon under investigation is embedded. With axial coding the investigator is concerned with identifying the relationship between categories in the context. The aim of open coding is to separate the data into concepts and categories. Axial coding is conducted with the goal of putting the data back together by forming meaningful connections between categories.

Following open and axial coding, it is not uncommon for the investigator to be confronted with numerous categories that have been derived from the data. The final level of analysis, selective coding, enables the investigator to identify the most central category and to write a story that relates other categories to the central phenomenon under study. The evolving story becomes the inductive theory, grounded in the collected data. Selective coding allows the investigator to tell they story of the phenomenon of interest. This process produces a narrative account of axial coding, in which conditions, context, strategies, and outcomes are identified.

As the data were collected and the texts of each interview transcribed, the transcripts were read by the investigator (current author). Portions of interviews (as direct quotes) identified as relevant to the phenomena under investigation were culled from the texts. This initial process consisted of identifying direct quotes or phrases, in the language of the participants, wherein they revealed or otherwise identified important ideas or concepts.

After multiple readings of the transcripts, first order repeating concepts were identified. Generally, these concepts consist of quotes from the actual transcripts, but may also be paraphrased to capture the meaning. For example, many of the fathers 
reported that raising a child with their partner brought the two men closer together, "I think it brought us closer together...we're very much a family now... and we foster that." As this same idea was repeated across interviews, it was labeled "Being A Parent Enriches Your Relationship With Your Partner."

The next step involved the identification of higher order categories derived from the repeating concepts. These higher order categories were based on implied or explicit ideas or statements that, according to Strauss and Corbin (1990) should be close enough to the actual transcripts that participants should be able to recognize and understand their meaning. For example, the concept quoted above, "Being A Parent Enriches Your Relationship With Your Partner", was grouped along with other similar ideas under the category "Becoming A Parent 'Legitimizes' Our Relationship and Increases Intimacy."

Finally, these higher level categories were then organized to give rise to theoretical constructs. These theoretical constructs should provide meaningful descriptions through which the social phenomenon under investigation evolves. A meaningful and descriptive narrative is produced by a "weaving together" of the constructs and provides a new understanding of the experiences of the participants.

\section{RELIABILITY AND VALIDITY}

In contrast to quantitative methodology, qualitative research employs different methods of ensuring reliability and validity. According to Rubin and Rubin (1995), qualitative methods should be transparent, communicable, and coherent. That is, another researcher should be able to understand exactly how the data were analyzed and verify it; the categories should make sense to both the participants and the researchers; and the categories derived at should be internally consistent, yet also reflective of individual and cultural differences. Results from an exploratory study can also be validated through future research that builds upon initial findings (Strauss and Corbin, 1998) 


\section{ETHICAL CONSIDERATIONS}

This research project was designed and implemented in accordance with the ethical standards for research with human participants established by the American Psychological Association (1973) and the University of Texas at Austin. Participants were informed of the purpose of this study, of the voluntary nature of their participation, the procedures established for ensuring confidentiality, and their right to withdraw from the research at any time. 


\section{CHAPTER 4}

\section{Results}

This chapter presents and illustrates the concepts and categories derived from the interview transcripts and introduces the overarching theoretical constructs. As transcripts of the interviews were analyzed, 37 general concepts emerged that were common across a majority of interview participants. After further analysis, these 37 concepts clustered into 9 categories. The related categories then gave rise to 3 higher-level theoretical constructs. The following sections each begin with a table depicting the theoretical construct and the categories that support that construct. Paraphrases and direct quotes from the interviews are used to illustrate the concepts that emerged from the interviews. These concepts and the related quotes serve to "bring to life" the data and capture the voices and experiences of the fathers. Following this presentation of constructs and categories, a theoretical model is presented in Chapter 5 along with a detailed discussion of the model. Prior to a presentation of the results, a profile of two of the participating couples is presented to illustrate the varied experiences of gay fathers and provide meaningful insight into the social and cultural phenomenon to be described.

\section{Stan ANd DAVE}

Prior to meeting Dave, Stan had been in a long-term relationship with a female partner. During this time, he participated in raising her son and greatly enjoyed the time he spent with the child. Stan always assumed he would one day father a child of his own. After much painful self-discovery, Stan acknowledged his homosexuality and came out of the closet. At this time, Stan felt that he would be forced to abandon his dreams of fatherhood. As Stan put it, “when I realized I was gay, I thought I had lost everything 
because I didn't think I could have a relationship, much less a child." At this time, Stan was unaware of any gay fathers, however he was well aware of society's attitude toward gay men and children. In addition, after coming out, Stan lost the support of his immediate family members, including his mother and only brother.

Shortly after coming out, Stan met and fell in love with Dave. After about a year of dating, the two men had a commitment ceremony that, to the two men, was the equivalent of a civil marriage. Early in their relationship, Stan had expressed to Dave his desire to have children. However, Dave was clear that he did not share Stan's enthusiasm for fatherhood and the idea was once again abandoned for Stan. However, as Dave puts it, "Stan has constantly been wanting children. He portrays it as he never mentioned it, but it was always an issue and it was always kind of being brought up." For the first nine years of their relationship, the two men continued to discuss the idea of having a child, often with long periods of silence and inactivity on the issue.

Around the time of Stan and Dave's tenth anniversary, Dave gradually became aware of the fact that many of their friends, both gay and straight, were beginning to have children. Dave's two best friends from college, both women, now had young children. In addition, two of his brothers each had a set of twins around the same time. Suddenly, Dave found his world full of children and as he puts it, “...it was just kind of miraculous what was going on. A lot of our friends were contemplating...getting pregnant...having children." One weekend, while at their country home, Dave told Stan that he was ready to seriously consider the idea of parenthood. Stan immediately contacted an adoption attorney and began the process of finding their child.

While prepared to wait years for an available child, the two men were surprised and a little shocked to be chosen by an expectant mother nine weeks after sending out their adoption brochure and letter. In addition, the woman was due to give birth in ten 
days. With the help of another gay couple, Dave and Stan began to prepare for the arrival of their child. Six hours after Joshua's birth, Dave and Stan met their son as well as the birth mother for the first time. Over the course of the next ten days, the new fathers spent time in an area hotel, even renting a suite for the birth mother, anxiously waiting for the birth mother's custody rights to expire. Both the men describe those ten days as "horrible" as they were constantly aware of the fact that they could lose their newborn son at any moment. At the end of the ten day period, the men returned home to begin life with their new son.

While financially and cognitively prepared for their new life, neither father was prepared for the immense emotional and psychological changes that lay ahead. While both men had promising careers, each in a professional field, they both agreed that they did not want their child raised by a nanny. Dave agreed to quit his job in order to stay home and raise their son stating, "...there will never be a time when someone's not home for him and ideally me." However, it soon became apparent that they would each have to define new roles and responsibilities not only related to childcare, but also related to the day-to-day running of their lives. As Stan puts it, “...there were some ground rules in the beginning, but they were pretty broad...the other roles, we played by ear and they're still not worked out..." Stan's point seemed to be that it is an ongoing and fluid process of defining and re-defining roles and responsibilities.

As the couple settled into their new lives, they also became aware of additional challenges. Their social circle changed as they began to lose contact with their single gay friends and they found themselves in the company of both gay and straight couples with children. Stan's relationship with his family worsened as his mother had no wish to meet her grandson and his brother flatly stated that this was the worse thing Stan could have done. In addition, Stan, always reserved, found himself thrust into the center of attention 
on many occasions as two men with a baby received stares, comments, and questions, both positive and negative. They are currently working to find ways to respond to these questions and comments, both to protect their growing son and to instill pride and dignity in him. Stan and Dave are also coming to realize the importance of a support network in their lives. All of these issues are likely to remain salient as their family matures and as social attitudes evolve.

\section{RICK AND TOM}

The experience of Rick and Tom is perhaps more indicative of a younger generation of gay men. Both were 30 when they decided to adopt, after having been together for about nine years. Both men acknowledged their sexual orientation early in life, Rick at 12 and Tom at 19, and neither reported denying or trying to alter his homosexuality. Rick and Tom both reported a desire to have children of their own from an early age, but each assumed his sexual orientation precluded such a possibility. Rick maintained contact with other children by working in children's theatre while a theatre major in college and also as a summer camp counselor. Later, he also worked as a nanny in both Chicago and the San Francisco Bay area. It was while working for a lesbian couple that Rick once again considered his desire to have children of his own and began to see this as a real possibility.

While on their first date, Rick mentioned to Tom his desire to have children. Rick, being very goal oriented, set his $30^{\text {th }}$ birthday as the deadline for having a child. Rick said, "I spent several years where I was sort of panicking, like, you know, all these gay men in their 40's or approaching 40, who were seeing the idea of raising children just slip away." Fortunately, Tom also shared his desire for children and their newfound relationship blossomed. Several years into their relationship, when Rick was 26, he became the donor for a lesbian couple desiring to have a child through alternate 
insemination. Being the genetic father of a child with which he has contact about once a month only served to increase Rick's desire to father children of his own. After much discussion regarding the method by which they would start their family, Rick and Tom opted for adoption as the most desirable method.

Around the time of Rick's $30^{\text {th }}$ birthday, unbeknownst to him, Tom placed a call to the San Francisco Child Project thus beginning their journey to adoption. A week later the couple went in for an informational session. A few months later, they were certified for adoption and their daughter Sarah arrived three weeks after the couple was certified. Rick and Tom admit that they received their placement rather quickly, with the whole process taking just about one year. Tom made the call the day prior to Rick's $30^{\text {th }}$ birthday and Sarah arrived the day prior to his $31^{\text {st }}$ birthday. While they were the couple ultimately chosen by the agency, they were one of five families wishing to adopt Sarah. After Rick and Tom had been chosen, the foster family with whom Sarah had been temporarily placed appealed to the court, also wishing to adopt Sarah. However, the foster family had not been certified to adopt by the state of California. Despite this fact, there was a real possibility that Sarah might come to live with Rick and Tom, only to later return to the foster family. During this time, Rick and Tom were told that the foster family was very religious and conservative and the social worker suggested that Rick and Tom not have any direct contact with the family. The social worker was concerned that if the foster family discovered that Sarah was being placed with a gay couple they might try to prevent the placement. Interestingly, the agency seemed concerned with protecting the gay couple and keeping the child with Rick and Tom. In the end, the judge accepted the agency's placement of Sarah with Rick and Tom.

Since Sarah has come to live with Rick and Tom she has been fully integrated into their lives in the Castro neighborhood of San Francisco. People who want to "see the 
baby" and interact with her often stop the family on the street. They have also put together a group of 10 friends, mostly other gay men, who volunteer to baby-sit so that the couple can maintain their policy of one date night per week. Sarah has also accompanied her fathers on group vacations with their friends. Likewise, the family is very popular at their synagogue and the outpouring of support from people at the time of the adoption was especially affirming for Rick and Tom.

\section{Categories and Related Concepts}

The following sections provide detailed summaries of the categories that emerged during data analysis, subsumed under their respective theoretical construct. Within each category are the concepts derived directly from the transcribed interviews with the fathers. These concepts are often drawn from exact words or phrases used by the fathers during the interviews. For each of these concepts, direct quotes are provided from the interviews to better illustrate and give life to the data. While the concepts were common across a majority of interviews, only a limited number of quotes are included below. These quotes were chosen because they serve to best illustrate the concept and category discussed. The code in parentheses after each quotation is a reference to the couple and the specific member of the dyad. A table summarizing the categories and concepts is presented along with each new category to aid the reader in interpreting each section. 


\section{Forging New Ground - Multi-Faceted Identities}

Gay Men Can't Have Babies

Two Men And A Baby?

Uncharted Territory - Rules and Roles

Table 3 Forging New Ground

\section{FORgING NEW GROUND - MULTI-FACETED IDENTITIES}

\section{Gay Men Can't Have Babies!}

For all of the couples interviewed, a major theme that emerged was the idea that they wanted children, but often did not think having children was possible because being gay and being a father were seemingly incongruent ideas. Several repeating concepts were reiterated throughout the interviews. These are discussed in the following sections and illustrated with direct quotes from the interviews.

Of the couples interviewed, at least one member of the dyad indicated that he always wanted to have children. For many of these men, they grew up believing they would always have children, with most beginning to seriously think about or plan for children in their 20's.

"I guess I have always wanted to be a father..."(1-1)

“...when I was younger, I always wanted to have kids. I wanted to have a big family..."(4-1)

"I think I always kind of had in the back of my mind that it was something that I would like to do..." (1-1)

"I had always thought that I'd love to be a father" (3-1) 
"I remember being in college and thinking how much I just wanted to have kids of my own" (7-1)

For these fathers, it is clear that they always had a sense that they would one day father children. However, as will be examined in subsequent sections, it was only the means by which they would do so that was unclear for many fathers.

While discussing their long held desire for children, many of these fathers indicated that their desires for children were influenced by early experiences with children. Some of the men grew up in large families with many brothers and sisters and often served as caretakers of their younger siblings. Others spoke about helping raise nieces and nephews or working as camp counselors. In all cases, positive early experiences with children strongly influenced their desire to parent children of their own.

"I was in the Big Brother program in the 80's and loved it." (2-1)

"I have four brothers, two of which have children...both sets of twins...it was just kind of miraculous what was going on..." (2-2)

"...when my nephew was born...I was really attached to him, and that gave me the idea, you know, that if it was possible for me to have a child, I would...it was just overwhelming how a child could change your entire life." (7-2)

Whether engaged as caretakers or merely as observers, for these fathers, exposure to and positive interactions with children played an important role in their evolution to parenthood.

However, coming to the decision to actually become a father was neither a quick nor easy step for many of the fathers interviewed. For the majority of these men, despite a strong desire to raise children, being gay and coming to accept their sexual orientation often excluded the idea of children, at least temporarily.

“... and when I came out it's kind of like, you don't really think of yourself in a family structure again. You think that may not be an option for you."(1-1) 
“...when I was younger, I always wanted to have kids, but then, you know, the whole process of coming out, and then I just figured I never would.” (4-1)

"I knew I wanted to be a parent, but I kind of didn't think it was possible, you know, because I came out on the East Coast and it was a lot less open environment..." (7-1)

Coming to accept one's sexual orientation represents a monumental developmental milestone for all members of a sexual minority. However, for the men in this study, the very act of doing so presented them with a new paradox: Does being gay mean I can't be a dad? These men were then faced with the task of integrating these two seemingly contradictory identities.

Often, after having either pushed aside the desire to have children because of the seemingly incompatible ideas of being gay and being a father or because of career goals, these men felt that something was missing from their lives.

"Then, by the time we had a house...We were establishing our practice, it's like, I mean, I wanted something more." (1-1)

We were just settling down... we had traveled and when we got that out of the way, we were kind of bored. Maybe it was kind of a natural progression... It was like, 'What now?'...that kind of next step for us...(4-2)

"But it was kind of an evolution of awareness that this was something that I could have in life." (3-1)

For these men, the desire to raise children represented an important "next step" in their development. After having achieved professional and/or personal goals, having a child was a natural achievable goal to work toward.

Even when one partner expressed a strong and life-long desire for children, the other partner did not always share this desire. In some cases, it took a lot of discussion before both partners agreed on the desire to have children.

"It was more my idea than (his)...You were very much against it." (1-1) 
"After about a year or two... of seriously discussing it, finally (he) relented and said he would go along with it." (1-1)

"But if it weren't for me, you would never have had children to begin with." (1-1)

“Well, initially I didn't want to. He worked on me for about three years." (4-1)

As with many couples, whether heterosexual or homosexual, the desire for children may not be shared equally between both partners. As the next section illustrates, there is often a great deal of discussion required before both members of the dyad agree on the decision to adopt.

Reaching the decision to adopt involved a lot of discussion, research and planning for these fathers. A great deal of discussion often took place prior to the final decision and commitment to adoption. Then, once the decision was made that they would have children via adoption, thus ensued countless hours of research and planning in order to pursue a successful adoption.

"...we started the adoption process...we signed up with adoption attorneys and started looking... We thought we'd try to meet a couple that had already adopted... and we found out which attorneys they were using...so then we sought out attorneys" (1-1)

"Actually, you did a lot. You did a lot of research on the Internet...looked at international adoptions...Romania." (3-2)

"It wasn't always in our relationship. It was just an opening up around us and then a personal realization for me that this could happen and...I think it was me saying why can't we do this thing? And him saying, "Yeah, I've always wanted..." that that kind of put it into gear." (3-1)

For the majority of these men, the idea of adopting represented a formidable task. Many were unsure of the legal and political climate surrounding same-sex adoptions. Unlike heterosexual couples who may be in high demand for adopting infants, adoption for these men required countless hours of research and planning. 


\section{Two Men and a Baby?}

A second category that emerged from the interviews concerned the reactions these gay fathers received from others. The idea of one primary caregiving father, much less two men with an infant, often attracts skepticism and disbelief from the larger society. These men were confronted by long-held social beliefs about fathers and the lack of a "mother" at many levels.

Often, in their daily social interactions, gay fathers are bombarded with the question "Where's Mom?" or "Giving Mom the day off?" These questions further underscore the societal belief that men are incapable of parenting an infant or toddler without the guidance of a mother or at least another female.

"It's more like the mother part and generally I think that's what other people, they look at us thinking, who's going to give motherly attention...(3-2)"

His partner further expounds upon this idea, stating:

A lot of women, you know, they see it as their role and somehow having a vagina means that you can mother. And so, if you don't have a vagina, you can't be the mother or you can't parent that way. You can't give motherly love. You can't give that kind of affection. You can't nurture that way. I think that for me that's been the most objectionable.... those kinds of statements...my interpretation is they're being threatened because we're saying you don't need a vagina." (3-1)

“...the first three months I was off work altogether. Going to the park and seeing the whole subculture of nannies and mothers with children and being the only male present and being asked 'Where's mommy?' or 'You took the day off to watch the kid?' and I would say 'No, I'm the stay at home dad' and then, not be embraced while you would see other women and children and it's a whole different interaction." (2-2)

'He made some comment about 'So, giving mommy the day off, huh?' And none of us said anything about it. And, it was like, clearly an issue for me and I'm sure it was for everyone else too. What I said was like, 'I don't want to deal with this." "(2-2) 
For stay-at-home dads or primary caregiving fathers, regardless of sexual orientation, there is a pervasive belief in our society that a man, let alone two gay men, cannot care for and nurture an infant. For two gay men, they further challenge this belief because "mommy" is not merely at work or away for the day. These men are demonstrating that two men can adequately care for an infant and that biological sex may not play as important a role as is commonly believed.

Furthermore, two gay dads present a seeming anomaly not only for the majority of mainstream society, but also for other gay men. Wherever they go, the reactions of others demonstrate that two men in the caregiver role to an infant is puzzling at the very least, and even upsetting to some. In addition, across the board, these fathers stated that some of the most negative reactions they encountered were from other gay men. Often, they were met with the question of "Why would two gay men want a baby?"

"We've always said that the biggest negative reaction we have ever gotten is from other gay men. Some are kind of like, 'why would you want to do that? You have everything you want. Why would you want to do that?' They just have no comprehension of why you'd want to do it. Other people feel, I think it's just kind of a sense that 'oh, they're just trying to be straight.' And gay men are much...more vocal about it. I think they feel freer to say what they think." (1-1)

"...to some of them, they think, it's just one more status symbol and like the ultimate gay status symbol is to, you know, heterosexualize your life." (1-2)

“...my friends at work were shocked that we were adopting a child. I guess because they don't know other gay couples that have a child and my best friend... all she was concerned with was the biological mother and that's all she would talk about...finally I had to confront her and say 'What about me? I'm adopting this child. This is my child.' It took her a while to accept that...(3-2)

“Our associates couldn't believe it...'I can't believe you guys have a baby. You guys have a kid?' I mean initially when he was an infant you have a dropoff of people...you always, you know, get the questions, they say 'Who's the mom, who's the dad?' those things. (4-1) 
Since the birth of a modern gay subculture following the Stonewall Riots of 1969, it has been mostly void of children and centered around adult activities such as socializing in bars and nightclubs. Only recently have gay men and lesbians begun to reclaim their right to parent and raise children. However, for some members of the gay community, the idea of children represents a challenge to the freedoms that have, in many ways, come to represent the gay male subculture.

While many of the men stated that they had made significant lifestyle changes before considering parenthood and that their involvement in the gay community had taken on less significance in their lives, for many men, becoming a parent further changed their place in the gay community. Strangers within the gay community may respond negatively to a gay male couple with children, as discussed previously, but many of the fathers interviewed also reported losing gay friends.

"Gay friends...some of them we cross the line with." (2-1)

"I think it was half have been "this is great." The others are kind of like... I'll support you as much as I can but..."(2-2)

"We can talk about (my son) but he's never met him (referring to a close friend). A couple of times he kept saying you know he should come to the house so he could meet him and always canceled. So now we basically don't talk anymore. It's like they don't really want to see your life with a child because then they are not familiar with that. (3-2)

We've lost a lot of our single... when you're a couple; you lose your single friends. We've lost a few of them since (the baby) and it's partially, we don't have any chance to socialize anymore. Part of it is that we just do more than they want to deal with. (2-2)

"You know, a lot of queens out there...really have an anti-parenthood mentality. They see us walking down the street, and you can see it in their faces like, 'How dare you bring this child.' Especially in the Castro." (7-2)

One father, who works with many gay men in his practice, found that his clients' reactions to him often changed once they found out he was a father. 
"I think the moment the child comes up in that office setting, it's a threatening situation. All of a sudden, I'm not quite as safe as they want me to be because all of a sudden they don't know if I am gay and if what they're saying to me is as safe as they want it to be." (3-1

The resistance to gay fathers within the gay community likely has parallels to the resistance experienced in the larger society. Gay men raising children within the context of an openly committed relationship is still a very new phenomenon.

\section{Uncharted Territory - Rules and Roles}

In addition to forging new ground by expanding their roles not only as gay men, but also as men in general, the men interviewed are expanding the roles performed by fathers. The third category that emerged, related to this idea, is that of moving into uncharted territory and expanding the rules and roles for each partner of the dyad. Despite societal obstructions to same-sex couples forming families and despite the trials and tribulations many of these men have endured, all of these families evidence an ability to thrive in the face of adversity. Faced with new challenges and often confronted with social disapproval or lack of social support, these men have embraced the opportunity to write the script of a new social phenomenon.

Due partially to the lack of scientific and popular literature about gay fathers and the absence of visible role models, these men were faced with both the challenge and the opportunity to make up their own rules about childrearing and parenting. In addition, they were able to forge their own definitions of "father" and the roles each would play. Sometimes, roles were determined by who was good at being "dad" and who was not so good at being "dad."

“...for us it was known. I said to him, I'll do $10 \%$ of the work. Before we even had the child, that was it. And every now and then, I do invoke the $10 \%$ rule. I've done my $10 \%$ and usually it's far more than that although he'll never give me that kind of credit. I'm invoking the $10 \%$ rule and I'm just like...I go somewhere. I just need to get out." (1-2) 
"I find it frustrating cause I'm not good at it. I don't like not being good at something, but it doesn't come naturally to me like it comes to him. So, I kick myself every now and then for not being a good dad... I'm not the good dad... my role in bringing up these kids is a lot more peripheral than his role and he is usually in hours before me...there'll be at least 6 or 7 nights out of a month I am not even here and he's never not spent a night under a roof with (our son)." (1-2)

"I had real faith that we could do it because of his nurturing ability and my kind of intrepid spirit too...you have to figure out if you think that your personalities can do it and that you have the capabilities of doing it and I think that's an important consideration too." (2-1)

"I was struck by this is once again gay men being limited to certain roles and not conforming..." (2-2)

"It started that way from the beginning where because I woke up so early and I work so many hours, he was more the responsible party for feeding at night, for waking up and feeding... and then because you were up at night, there was more really, kind of bonding time so what happened in terms of their relationship was his relationship with (our son) really took on much more of a mommy relationship and me as a daddy relationship and it's been that way ever since." (3-1)

While the classical "mother" and "father" roles are no longer valid for the majority of American society, many parents still struggle with attempts to adhere to some part of these roles. For the men in this study, their roles may not be determined or influenced by gender, but they must still work to define their roles as parent and as "fathers." For many men, it appears that the lack of rules and prescribed role behaviors present them with the opportunity to define roles and responsibilities based on what is truly adaptive to the personal skills and life circumstances of each man.

The ways in which parents handle the multiple responsibilities of childrearing can involve many arrangements and the help of many people. The same is true for the gay dads in this study. However, another distinct theme that emerges is that of the primary care giving father or PCGF. Whether it was explicitly decided before the child was born or whether an implicit or explicit arrangement evolved over time, one member of the dyad takes on the task of primary responsibility for the child or children. While some of 
the couples interviewed were able to hire a full or part-time nanny, the majority of couples were faced with the decision of "Who stay's home and who goes to work?"

"Well, it's never been an issue for us who was going to be the primary care giver. Where the conflict comes for me... and what any working parent has to deal with is trying to maintain a career as well as be a primary caregiver for the kids. That's really hard." (1-1)

"What we've done is actually taken on a nanny four days a week and I work part time two days a week and...(he) travels probably four days a week. So, he's around the weekends and gone the rest of the time. So much so that in some respects I am kind of a single parent during the week." (2-2)

"So, generally the household stuff and the general child rearing stuff falls on me just because I happen to be here all the time. And my job isn't as stressful as (his) so I have more energy when I come home." (3-2)

"But then there was the economic thing where my hours supported the family more than his hours did and that was something that was a force in it." (3-1)

"I'm the stay at home dad, so you know, I'm here taking care of (the child)...he makes more than me...we could have hired a nanny, but having someone else raise our child, I mean, I come from a big family that, you either did it or some of your relatives did it" (7-2)

Much like heterosexual parents, for these couples, the roles of provider and caregiver are often decided based on economic factors. However, whereas the decision for heterosexual couples may be influenced by one parent's biological sex or gender, there is no such clear delineation for these men. While gender role theory predicts very specific parental behaviors based on the sex of the parent, the fathers in the current study are creating a new definition of fatherhood that predicts behaviors based not on the sex of the parent, but on developing adaptive behaviors based on the skills and desires of each individual parent. The topics of division of labor and primary care giving fathers (PCGF) will be discussed further in the following chapter.

An additional struggle that is often ongoing for these fathers involves negotiating the daily challenges of being a parent. Often this entails prioritizing the needs of the 
father (often those of the PCGF or stay at home dad) versus those of the child. In addition, one father often made both personal and career sacrifices in order to accommodate his new role in the family.

“... the hardest thing is I just don't get sleep anymore. It doesn't happen. You can't go out. You go to sleep and there's not much to do." (2-2)

"Even for me it is hard to stay at home and it's a constant question of should I be out there working five days a week? I don't think that's ever gonna get locked in. I think it's how do I feel right now. What does he need? What do I need? What does the house need? So, I think that decision is gonna constantly be readjusted." $(2-2)$

"And I am so into my quiet time now. I want my quiet time no matter what and I get irritable if I don't get it. Because that's just my only time to me." (3-2)

"It is exhausting. I mean, (he) does it definitely more than I do...but when you have a little one the whole day by yourself, the ones you really recognize and respect are the single mothers." (3-1)

All parents may struggle to maintain some semblance of life as they knew it prior to becoming a parent. For most families, the person who struggles the most is likely to be the mother. However, in the case of these fathers, we find they are making decisions and sacrifices not generally associated with fathers (e.g. career vs. family; personal needs vs. needs of the child). It is likely to be an ongoing challenge for these fathers as they continue to define new roles for themselves and possibly for fathers in general. These challenges and the implications of these challenges will be examined further in Chapter Five. 


\section{Creating A Family}

Families of the $21^{\text {st }}$ Century

A Family Story

Family, Community \& Support Systems

Table 4 Creating A Family

\section{Creating A Family}

\section{Families of the $21^{\text {st }}$ Century}

Perhaps because of their own experiences with adversity and related membership in a marginalized group or perhaps because of the diverse methods by which they created their families, the idea of valuing diversity in their children's lives emerged as a distinct category. For many, their children were placed for adoption in less than ideal circumstances and many of the children come from varied backgrounds. In all cases, these men appear to be committed to raising children who respect and value diversity.

Strikingly, these men evidenced a willingness to consider a wide range of adoption possibilities, even in cases where most prospective parents would be discouraged or unwilling. However, many of the men, due perhaps to their research prior to beginning the adoption process, also knew their own personal limits.

"Both the mothers were incarcerated during or after the pregnancies so you're trying to figure out is this a genetically well put together person in a bad situation or is there some real genetic psychiatric problems with this person that I'm afraid to take on in a child. "(1-1)

"We did a lot of research on that (methamphetamine abuse) and we were lucky with (our son) because his mother was in jail." (1-1) 
"We actually called around to a couple of OBs and Pediatricians to get their opinions. You know, this is what we're dealing with. What do we do in this situation?" (1-2)

"But we also during both adoptions made the decision that no matter what the baby came out like we were taking it. By the time we had committed to the birth mother in taking the child, we said, no matter what handicaps the kid had, even if its obvious when its first born, we are taking the child. But I took it the same way as like, looking at natural children. You're taking your chances too. So I felt like at that point, you just take your chances and get what you get." (1-1)

"(the baby)...could be drug exposed, HIV positive...We would take children who had developmental disabilities as long as they weren't severe. We said no to Down Syndrome, no to Fetal Alcohol Syndrome." (4-1)

"I got a call and the only information that they had was, 'We have a drug-exposed 2-day-old baby boy.' And that was it. I had no idea on ethnicity, race, or anything.... So, I just called them back and said yes." (4-1)

"...we knew he was drug exposed during the pregnancy. We know that mom had done pot and crystal meth. We suspect Heroin also." (4-1)

"...she (the birth mother) was in a situation where the boyfriend that she was living with put her out on the street because she had told him she had an abortion, and she hadn't... and she had actually been on the street for 10 days and then contacted an adoption agency. And they didn't want to deal with her because there was drug use early in the pregnancy." (7-1)

Throughout the interviews, the men evidenced an overwhelming willingness to consider adopting a wide range of children. Not one father spoke of looking for the "perfect" baby. In fact, upon discovering that their new son was a blond haired, blue eyed child, one father remarked: "We went there and we met him, and...he had a head of blonde hair, blue eyes...the pale skin, not what we were expecting..." (4-1). This father's comments allude to the well-known fact that "perfect" babies are typically not placed with gay couples. 
All of the men interviewed were also willing to consider a child of a different race or ethnicity and five of the ten couples ultimately did adopt a child of a different race or ethnicity.

“...they (speaking of the birth parents) wanted something much freer and much more Berkeley-ish...cause they were like Berkeley kind of people. They wanted a freer environment and I think they felt with us, he's Jewish and I'm Filipino and she felt like it would be nice if her child grew up in a diverse household." (3-2)

"We said we'd take a Hispanic baby... we got a call on an abandoned Hispanic baby boy two weeks old. And by the time... our agency got a hold of me and I got a hold of (him) and we got back to the agency, the child had already been placed with somebody else" (4-1)

"But the entire family was totally supportive...I told them our baby that we might adopt might be a different race...And the situation in Mississippi was an AfricanAmerican baby..."(7-2)

Perhaps because of the diversity of this sample or perhaps because of their own experiences as a minority group, these men displayed an appreciation for multi-ethnic families and a willingness to adopted children of different races and/or ethnicities.

Related to the previous category, an idea often repeated was that these men sought to raise children who are open minded and sensitive to others who are of different backgrounds or of different abilities. These fathers want their children to develop an appreciation for diversity in their lives.

“...they have a really good public school system where he wouldn't have to go to private school and as we looked everyone was white and everyone was genetically identical and very homogenous. Although they'd love to have us, we'd be that cute gay couple with the really cute little kids. We don't want to be like, the little darlings on the block." (1-2)

"Then there are...gay dads that only want to associate with gay and lesbian families. We want him to be exposed to everybody." (4-1)

“...they're not allowed to make fun of each other. They're really strict on that kind of stuff with the kids. So that was another reason in choosing that particular school." (4-1) 
Similar to their willingness to adopt children of different races or ethnicities, these men also want to raise children who are open-minded and sensitive. It is tempting to believe that all parents would want to raise children who are sensitive and open to others who are different than themselves. However, as the above quotes illustrate, these fathers are making a concerted effort to achieve this goal in their children as evidenced by the types of schools they send their children to and the types of communities in which they are raising their children.

\section{A Family Story}

Not surprisingly, the methods by which they created their families and their experiences along the way were major themes across all interviews. While each of the families interviewed had a unique story to tell about the evolution of their family, there were certain commonalities across a majority of the families. For many of these men, becoming parents required much determination as well as great investments in both time and money. The following sections serve to illustrate the common pathways these men traveled in creating their families.

Perhaps the most common topic across the interviews was the characterization of their adoptions as an emotionally and financially exhausting process. The majority of the men pursued private adoptions with all of the costs associated with such adoptions. However, both private and public agency adoption exact an emotional toll on prospective parents.

" $\$ 5,000.00$ - $\$ 6,000.00$ for legal fees and $\$ 5,000.00$ or $\$ 6,000.00$ for the search for a year...you have to hook up with an adoption agency because you have to have a home study in California. And then when we got (our son) in Nevada we couldn't leave as gay parents from Nevada so (our son) left Nevada in care of the adoption agency and we were agents of the agency." (1-1) 
“... and then you support the mother financially for three months post partum and basically...from the moment you make contact with her. You know, as far as paying all of her day-to-day living expenses." (1-2)

"I contacted her (the attorney) on September 15 and I remember that day cause I was in a board meeting and I took 5 minutes out of the board meeting to make the call and ended up coming back in with tears streaming down my face because I'd made the call." (2-1)

"... at one point we had been with him (our son) ten days in the hotel and it had suddenly occurred to me after we had to sign this paper that just made us both like grey, that we might have to give him back..." (2-1)

"Then, the mother had to go through a little bit of counseling but by that time she was 38 weeks...things just happened very quick and we were there the day after and the hardest part was the day of getting to take (our son) home and they were really struggling that day... sometimes it's just easier if the biological parents are, that there's something wrong. And there was nothing wrong here and that's why these question marks for me, you know, I have question marks." (3-1)

"But San Francisco is like the most liberal county as far as birth parents' rights. They give them every opportunity under the sun to be able to get the child back. I mean, it can be a very lengthy, lengthy process. So, we didn't know how long, you know, it was all new to us. We went from one thing to another." (4-1)

"I mean there was 18 months where we had to completely watch every step, everything we did, and they were just waiting for us to do anything that was far out so they could pull him out of our house... You know, they made things as impossible as they could for us during the whole time." (4-1)

"I mean it was especially hard on (him) emotionally... Not that he didn't want (our son), but it was just like if they did one more thing, it was just like, I mean it was really, really difficult. And I think we still, even though it's a year and a half later, have the effects from it." (4-1)

“...it was very traumatic for us. It felt like we lost the baby... and I think for a while it sort of dashed our hopes...for a while we did not want our letters sent out. We were pretty much in isolation. We decided that we were going to wait a couple of months. I actually went to therapy, too. And my first year of taking Prozac ever." (7-2)

One could correctly argue that adoption can be a lengthy and exhausting process for all couples who adopt. All prospective parents deal with home studies and court 
hearings. However, two gay men who are adopting a child likely receive a level of scrutiny beyond what is warranted. Having to deal with a system unaccustomed to samesex couples can result in excessive emotional and financial strain for these prospective fathers.

Along the way to creating their families, these men often had to interact with a complicated and cumbersome legal system. A major theme in each of their stories involves that of being educated and prepared for multiple legal hurdles and realities.

"We knew she (the lawyer) was very experienced and I think what sold us is that our neighbors down the street are lawyers themselves. So we thought...since they were attorneys themselves, we felt pretty safe and I think not a lot of lawyers have experience with gay couples but she seemed to have the most of any...we had heard the names of some other people...I didn't interview cause I just didn't feel like they had enough experience." (1-1)

"(Our son) came from Florida and Florida is a very difficult state. I mean, gays cannot adopt there. They have some of the hardest laws. She has worked all around and it wasn't an issue." (1-1)

"...it can be a very lengthy, lengthy process...we were informed of that. So, we didn't know how long...it was all new to us. We went from one thing to another." (4-1)

"A year-and-a-half...it involves a huge, lengthy legal battle..." (4-1)

"We also came to find out that our agency was like the worst one that had the worst relations with the county already...they hated our agency...they did a home study, and the county rejected it." (4-1)

While any adoption can be fraught with legal problems, gay fathers need to be particularly informed about the legal process. Due to homophobic and anti-male adoption beliefs and practices discussed previously, the need for vigilance during the process is an added layer of stress for many of these fathers.

One way that prospective parents can prepare for the possibility of legal obstacles in their quest to adopt a child lies in their choice of an attorney to handle the process. For 
this reason, it is very important to choose an attorney who is well equipped to handle the legal challenges sometimes associated with placing a child in a home with two parents of the same sex. Many of the fathers spoke at length about the importance of their relationships with their attorneys.

"She's very confident when you go to these meetings and we were like what are the odds that we are going to find a baby. She goes 100\%." (1-1)

"That's why we used her again for the second adoption because I was very impressed with the rapport they had with the birth mothers... because you are dealing with a pretty marginal group of people...for the most part." (1-1)

"...when we went in to see (the attorney)...he used to be the city attorney for the county that handles all these type cases. He used to be the team we were going to be fighting. He knew everybody. He knew mom's attorney... luckily for us, he was very good, he was good friends with mom's attorney and dad's attorney." (41)

“...that was our attorney's strategy, he's like just listen to me, listen to me. Now when they're saying this stuff about you, just, you know, if you need to explode, let it out on me..." (4-1)

"...if we had not picked him (the attorney), I'm convinced we would not have (our son). There was nobody else that could have basically orchestrated with the contacts that he had, the connections of knowing everybody, knowing how the system worked and keeping us under wraps also and keeping control of us..." (4-1)

“...where they got more leads of potential...birth mothers...was by working with a particular attorney in the city here named... and apparently her law office...they were like one of the first law firms in the area that were doing gay and lesbian adoptions." (7-1)

she kind of acted more as a consultant to us and let us kind of manage the relationship with (the birth mother), and we discussed that. She said, you know, it seems like...the less I need to be involved here is probably better because... you've got a good relationship going. But, there were times where... we didn't know what was the right thing to do and everything, and she advised us..." (7-1)

While the use of an attorney is not always required, they can serve as a very important ally to the fathers during the adoption process. Given the often unexpected 
legal dilemmas that can arise along the way, prospective gay fathers need to be particularly astute in their choice of attorney.

Once a qualified attorney is identified and the process of locating a child has begun, there is the potential for roadblocks and setbacks along the way. For many of the men, these challenges represented trying and often deflating times.

"You know, you hear all of these horror stories about adoption. She told us that those horror stories occur because they had bad lawyers, bad counseling." (1-2)

“...we'd meet them...these guys who went through like 16 failed attempts or something." (1-1)

"... at 3 months, we had been saying, what's the permanent plan for this child? When they go in foster care, then they're supposed to come up with a permanent plan...the county worker didn't know what was going on. He was mad at us...We started pushing...San Francisco County.... and we kept on kind of getting the brush off. And then...they say... we're going to see who the permanent placement is going to be. And we're like what do you mean, who the permanent placement, you know, why aren't we the permanent placement?" (4-1)

“...we're trying to find somebody who will do a home study for us, which nobody will because the word had already been put out by the county that anybody does a home study for these guys aren't going to get kids for further placement. So I mean, anybody who was going to do our home study, any agency, would be blackballed." (4-1)

"...we had an interrupted adoption the day after the baby was born, we were matched with the birth mother. But three days after the baby was born, the day we were supposed to come home with the baby from the hospital, she changed her mind. So that was hard." (7-1)

Fortunately, adoption is not a long and difficult process for all fathers. Some couples reported that their adoption process was fairly easy and painless.

“...we thought years and years and years. I figured it' $\mathrm{d}$ be a couple of years before it happened." (2-2)

"Nine weeks later, we get the call. M from Minnesota had selected us and a straight couple." (2-1) 
"It was probably the easiest adoption compared to, I don't know, 99\% percent. I mean, things just flowed for us so it was very easy." (3-1)

"...we kind of walked into a situation where our entire pregnancy was about 2-3 weeks... things just happened very quick..." (3-1)

Prior to completing their adoptions, many men had to confront homophobic and/or anti-male adoption practices or the beliefs of individual adoption workers and other professionals. In some cases, the states from which the children were adopted have laws that explicitly prohibit either gay individuals or same-sex couples from adopting.

"It was a little tricky cause both our kids came from different states so there was legal finagling to do to get us into the state with the boys." (1-1)

"...that's the person's perception...(our son) who is the blond, blue-eyed baby, he should be given to a straight couple." (2-2)

"This is a friend that we both went to visit and she said something in the order of I didn't know that they gave the perfect baby to gay people." (2-1)

"It's like the same way they treated us at the hospital when they realized we were the ones who were adopting the child...they were condescending...'Do you know what you are supposed to do?' 'Do you know how to do this?' 'Are you sure you know how to do this?"' (3-2)

"And what we come to find out also is it's very easy for gays and lesbians to adopt, as long as they adopt hard to place kids." (4-1)

Despite the fact that all of the men in this study reside in the San Francisco Bay Area, generally thought to be a permissive and accepting area, they were still faced with discriminatory adoption practices. Despite statements from the Child Welfare League of America and other such groups that explicitly discourage placement workers from using the sexual orientation of prospective parents as the sole reason to deny placement of a child, such practices still exist.

Once the legal challenges to forming a family are met, these fathers are then faced with the emotional particularities of creating a family bond. Despite limited progress in 
the area of marriage equality, same-sex marriage still is not recognized in 49 states. Due to the lack of civil and legal recognition of these families, these men have made a deliberate and concerted effort to create a family based not only on legal obligations, but based on a deeper sense of commitment and ideals of family.

"So there's all kinds of combinations of families and at least, as far as I can tell talking to the psychologists and psychiatrists I know, there's no evidence to say that one way is innately superior to another. So, there's some empirical data that says that we're not bound and determined to screw him up." (2-1)

“...when we had our commitment ceremony, I said 'God can't not like this. God loves love in my universe.' I can't imagine that God would want anything other than the kind of love that we and our extended family give to Jack. That's the most wonderful thing in the world. Everybody who knows him adores him and adds something to the mix for him. That can't be wrong. At least, in my universe it can't be." (2-1)

"It doesn't make sense to me...that having two people who love each other focus on raising a child with love with an extended family that loves him in all kinds of ways...that can't be bad. One of us is not a female and there are two males here. So, but, there's just too much data that says that a family is a lot of other things other than two people of opposite gender getting together. So, and that's what a baby needs is a family, isn't it?" (2-1)

“...it was also good when she left (the birth mother), for us to start our bonding process with our baby..." (7-1)

Several of the couples interviewed had commitment ceremonies as public expressions of their relationships. Many were also registered as domestic partners in San Francisco. However, they were all denied the legal definition of "next of kin" that is granted through civil marriage. For these men, their definition of "family" is much more broad than what is recognized by legal jurisprudence. When speaking of their families, they all emphasized the psychological bonds that each member shared as opposed to the blood bonds or legal ties. The method by which family "legitimization" was accomplished varied with each couple. Some couples legally changed their surnames so that all members shared the same name. One couple was added to the child's biological 
family tree. Still another family celebrates "gotcha day," or the day the child came to live with the two men. Perhaps one father sums it up best saying, “it doesn't matter who's raising a child, it's all about love."

\section{Family, Community \& Support Systems}

Another common theme related to the creation of these families was the role of family, community, and support systems in their lives. With the exception of two of the men interviewed, all men reported that their families had been overwhelmingly supportive of their decision to adopt. Even in instances where parents or siblings were initially unable to accept a father's sexual identity, a new child in the family represented an opportunity to overcome such differences.

"But we've had nothing but support from our families and friends and it has never been an issue." (1-1)

"...my family has been more supportive than I would have ever thought. So, that hasn't been an issue." (2-2)

"And my father's around with a girlfriend of twenty something years and they have all accepted it. As well as my twin brother who lives here in the city is one of the godfathers. His wife is a godmother to (our son)." (2-2)

"I have a lot of issues with my family...But my parents have been very supportive the whole way and try as best they can." (3-1)

“...he's been accepted by each one of our families, from the moment he was brought home." (4-2)

“...my family supported me being gay and it's been very overwhelmingly positive...the people that I though were going to have problems, didn't have a problem... Of course, my mom...doesn't want her kids to be...hurt...but everybody in the family has been very supportive." (7-2)

“...my mother passed away in 2000...I think if she had gotten to see him...she would have been totally supportive... and with my family back East...we talked about...just how happy my mother would have been... and my aunt and then my cousins back there...he's the new generation of the family..." (7-1) 
While having a child may represent an opportunity for a closer connection to one's parents and siblings, the closer sense of connection for gay men may be more profound because their parents may have given up on the idea of grandchildren when they learned of their sons' sexual orientation.

Unfortunately, a few of the men reported that their parents or families did not react positively to the adoption of a child. Despite even some concerted efforts on the part of these men, some families continue to withhold support and acceptance.

“...my mother will not allow us to come to her home...because then her friends will know that she has a gay son. We hoped it was going to change but it's never really going to change. My mother was really not very nurturing even if you go way, way back." (2-1)

"...we told my mother first. She was shocked but then she was fine. The hard part was trying to tell my father. Eventually, I had to tell him that we adopted a child... and his first comment was why would you do something like that? And ever since then, he is slowly realizing that it was not just me who adopted a child... and finally I had to tell him that I was gay. But from then on he decided that he doesn't want to see me in this atmosphere." (3-2)

“...I feel like I've been abandoned by these people. My mother and I used to be close...she hasn't...Nobody has ever called me. I don't even call them. Nobody asks about how he's doing except my sister and my brothers." (3-2)

"...I have another brother and sister that are born again Christians...they didn't believe that we should have (our son), he should be with a straight couple." (4-1)

For the men whose families have been unwilling to accept them and their children, the ties to "chosen" family are likely to play an increasingly important role in their lives and the presence of such ties may have mitigating effects on the rejection they have experienced from their own biological families.

While most of the men interviewed reported close familial relationships prior to having children, the majority of men also indicate that having a child resulted in an even closer connection to some, if not all, members of their family. 
We certainly visit more often now because they want to see the grandkids. I mean, our families have been totally accepting. They accepted these kids just the same as any other grandchildren. (1-1)

And they feel closer to you because they've realized you're sharing a similar experience to what they have actually done too. As well as your brothers and sisters. If you haven't had kids, it's kind of hard to know what a parent goes through first hand. So, it's definitely made us closer. (1-1)

"Then I had some cousins over here who didn't know I was gay...but they were accepting of it. My sister was... her husband and her kids... all of a sudden, it opened up this other side that I didn't have before which was basically being honest to my family." (3-2)

"But I told my mom that I wasn't going to bring the child into a home where it was okay for us to be a family sometimes and not okay other times. Either accept us as a family all the time or not. So it's changed with them for the better, and it's all because of him. Not because of us, but because of him." (4-1)

"I think I go home more." (4-2) His partner concurs, saying "You're closer with them or you talk to them more." (4-1)

"...because the baby was there, it kind of put a whole different spin on the Passover...my aunt...for her...the baby was the center of everything. And I think it would have been really difficult for her for this Passover if the baby wasn't there...his name is Hebrew, it means gift, and so he really was a gift in that sense." (7-1)

"...I mean we always connected in a certain way and, you know, we've always been very close, but that's like the first time that we ever really, really connected..."(speaking of his mother) (7-2)

For some men, there was a fundamental shift in their relationships with their parents or immediate family members. In some situations, damaged relationships were repaired with the arrival of a grandchild or a niece or nephew. In other cases, close relationships became even closer due to the shared experience of parenthood.

In addition to strengthening family bonds, these men gradually came to realize they had more in common with other people who had children, regardless of the sexual orientation of the parents. 
"I think whether you're straight or gay, once you have children, you don't socialize with anyone except people with other children because...your whole life is the kids...We have become much closer friends as a result of having children." $(1-2)$

“...you are just around more people with kids and most people with kids are straight..." (1-1)

"You end up talking to them and being with them socially because we're all watching kids together." (1-2)

"...like the friends I have at work who are gay...the ones who are in long term relationships are more accepting of the fact that we adopted a child as opposed to the gay single friends that I have." (3-2)

“...we finally have this relationship with this other parent who is so comfortable with gay couples....and (our son) happens to be best friends with her son...eventually we're going to have like, our own small little group of friends again." (3-2)

...the people that we make friendships now...they have the...common kid factor. They want one, they have one, or they just want to be around one... so people that are going to hang with us are going to hang with him (our son)." (4-2)

While the gay male subculture is often characterized as being a somewhat insular community of single men, the experiences of these fathers indicate that the shared experience of parenthood can transcend social barriers between "gay" and "straight."

For all of the couples interviewed, adopting children also provided a sense of legitimacy to their relationships, and often resulted in an increased sense of intimacy between partners. Same-sex relationships, especially between men, are often viewed as short-term and transient in nature. Sharing the task of raising children may provide a sense of permanence and of legitimacy, both to the couple and to the larger society. One method of achieving status as "legitimate" parents is through joint adoption or secondparent adoption. This ensures that both men have the same legal standing not only in terms of their rights, but also in terms of their responsibilities to the child.

"I think it brought us closer in a way..." (3-2) 
“...we're very much a family and the relationship changed cause it's a triangle now and we foster that. We're very into being a family... we're very strong as a family unit..." (3-1)

There are certain states...not every state you can adopt as a couple. Sometimes one will have to adopt and then the other one can adopt later. But in California you can adopt as a couple. (1-1)

"It was a two-parent adoption. We didn't have to go through a second parent adoption, and they put us both on the birth certificate..." (4-1)

"...we wanted to have equal legal footing (as parents)...that was one of the things we were really glad about this being completely a California adoption..." (7-1)

One of the many unique features of these families is that both fathers had the option to legally adopt their child. Many states do not allow two parents of the same sex to adopt a child. As indicated by the statements above, such discriminatory practices may severely undermine a sense of permanency in the family.

While the overwhelming majority of couples interviewed participated in open adoptions, their levels of communication with the birth mother (both before and after the adoption) varied greatly. The majority of families felt that it was important, both for the child and for the adoptive parents, to have some sort of connection to the birth mother and/or the birth mother's family. However, not all fathers were comfortable with a completely open arrangement.

"So we tried to pick the middle name to commemorate the birth mother. Which gives them... a little bit of a history... maybe it'll eventually help put it all together for them." (1-1)

"his birth mother is a sister of one of my patients and I have taken care of this patient for many, many years and I know the family quite well..." (1-2)

"She didn't know what relationship she wanted with (our son). She didn't know that she wanted her daughter to know about him. She still doesn't know but I think because we were more open to it she's more open to it now..." (2-1)

"we have seen the birth parents... once or twice during the first year and the second year we sent pictures and then..." (3-2) 
"I would not feel comfortable with an open situation. And what will happen will happen but I definitely wouldn't be very happy in that kind of situation even though the social worker who interviewed us for the home study was kind of pushing in that direction." (3-1)

"...it ends up that he knew the birth parent from years back when he did needle exchange volunteering... And knowing him through the needle exchange stuff made her much more comfortable with us." (4-1)

"We have contact with her (the birth mother's) grandmother up in Washington, who has sent us down pictures of the family, and who is kind of writing a family history for (our son) so he will know, if he wants, information on his blood relatives and who, when, where and what they came from. But that's the only contact we have. It's just phone calls now, e-mails, and just sending us pictures and stuff." (4-1)

"We know her parents. We have a relationship with them today... one of the things that impressed her about us was our willingness to maintain contact after...the baby was born." (7-1)

"We were pretty much parents for her... and still...she calls us up before she calls her own parents, running stuff by us, you know, even now." (7-1)

"And her (biological mother) grandmother pulls out this bag and says I have something for him...It blew us away. This is his biological great grandmother...pulled out of the bag this quilt that she has made for him. She makes something like this for all her grandkids. She said he wasn't going to be any different." (7-2)

"And they presented us with the family tree... so that he'll have some knowledge of his biological background. But then the wild part is that they put us in that family tree." (7-1)

The levels of connection and communication with the birth mothers varied greatly within the sample. However, contrary to long established adoption practices, all of the men believed in some level of open adoption.

None of the men interviewed had any prior parenting experience. So, not only were they becoming parents for the first time, but they were doing so in a new and often socially unacceptable manner. As with all new parents, it was important for them to find 
role models and sources of information to assist in raising their children. Sometimes, this also involved seeking out maternal influences for their children.

"Parentingmagazine.com, Parenting Magazine, books. Mostly books and then mothers that I talk to at work... we basically have the same stories. So I talk with them mostly about child rearing now and I enjoy talking to them about it because they know a lot so far." (3-2)

In terms of dads...I don't have any close...Like, Bill and Ted are friends of ours... Bill and I talk a lot about child rearing stuff but in terms of advice, I would go to my female friends more. I think it's a psychological thing...I don't know yet if it's because I automatically go to a woman or because they're my closest friends." (3-2)

"I mean we have some other parents that we talk to... we talk to our friends about issues that are going on..." (4-1)

"It's more maternal than any other schools. It's predominantly women who run the thing. But we looked at it because it is more maternal and so we're just kind of like rough, and he needed that other part. And it works." (4-2)

“...we wanted him to have a maternal influence. That was important for us." (4-1)

"My mom, my family, my sisters, you know, they talk to me a lot. I mean I've been there for raising their children, but this is the first like 24/7 for me. And it does make a big difference. I call them up and ask them a lot of questions, you know, what to expect, what not to expect, when should I do this..." (7-2)

"I think that's our primary source, and then, you know, books and the Internet and...I mean we've got some advice from his family, that we've chosen to...call suspect..." (7-1)

While some gay men were able to identify people to whom they looked for models on parenting, many also spoke about the lack of gay role models. For them, parenting may seem like uncharted territory.

As discussed earlier, many of these fathers reported a sense of being new pioneers in uncharted territory. When seeking out role models and support systems, they may be struck with the reality that there are not many families that resemble their own. However, 
at least in the San Francisco Bay Area, the numbers of such families are increasing and may offer additional means of providing support to future gay fathers.

"But since then, we went to a picnic a month ago and there was like, one's on their $3^{\text {rd }}$ and $4^{\text {th }}$ child and there were $40-50$ couples." $(1-2)$

“...we don't have a huge circle of people around us. There are things...like Our Family where we could have a lot more connection if we wanted it...I don't think anything's gotten in the way of us making those kinds of connections other than the type of people we are and how difficult it is to make those kinds of connections." (3-1)

"...we definitely have I think a good group of support people, but it's all because of (our son)...I guess they were kind of friends before they were acquaintances, now they've become stronger friends because of (our son)." (4-2)

For all families, connections to other families who may be similar to their own can play important roles as sources of support. However, for families headed by two fathers, such relationships may be especially important as they continue to navigate through the uncharted waters of child and family development. 


\section{Transformation and Rewards}

Personal Growth and Challenges

Adaptive Responses to Social Forces

Visibility and Social Activism

Table 5 Transformation and Rewards

\section{TRANSFORMATION AND REWARDS}

\section{Personal Growth and Challenges}

Perhaps not surprisingly, and not unlike heterosexual parents, all of the men interviewed identified the theme of immeasurable personal growth associated with being a parent. Often, this sense of personal growth was unexpected and surprising or was more far-reaching than anticipated. In addition, many men stated that becoming a father was the best thing they had ever done. For some men, being a father has become the accomplishment of which they are most proud, surpassing even career achievements.

The sense of personal growth and the manner in which these fathers described such growth varied across the interviews. However, becoming a father represented a developmental milestone for almost every father interviewed.

“...the couples that I know that don't have children...there's a level of selfishness that I really don't like and there was a level of selfishness with us that I didn't particularly like either...it's like everything becomes too precious or something... and we have a two year old here and...there's something a little chaotic about what's going on right now which is kind of fun... You have to be a little more inventive and a little more creative and some of the couples that we know that don't have children, I look at them now and I think...I wasn't sure I wanted to go in that direction." (2-1) 
"...not wanting to be childless... and end up being the kind of highly rarified queens was not something that I was at all interested in...I like what it's doing because it is loosening us up a lot." (2-1)

"I think it's interesting finding out more about yourself as you go along and I do...I'm amazed that I'm enjoying it as much as I do. I didn't expect that. It's fun and that wasn't what I expected." (2-2)

"...parenting...made me understand me more because it brought out the worst and the best and then I get to see this side of me that I've never seen before. To learn from it and so I think it's the best thing that's ever happened." (3-2)

"... some of the selfishness that...was there before, and I'm not saying all of it, is that it has gone away, you know. I think about both of them a lot more and decisions and...it's like I've become much more aware of financial planning and things like that, you know, the estate planning now and all these things...You grow up quite quickly." (7-1)

As the quotes above illustrate, there is often a sense of personal growth associated with parenting. However, personal growth does not always come easy. While some of the fathers report that being a father is likely the best thing they've ever done, many also report that it is the hardest thing they've ever done.

"It's the hardest and most gratifying thing we've ever done and I don't think my life would have been complete without it." (2-2)

Nothing has prepared us for the reality...it's the best thing that's ever happened to me and the worst thing that's ever happened to me...it's shattering... what it does to your life... in a positive way and not so positive in some ways. (2-1)

"It's an incredible, incredible thing to take on...just an incredibly exhausting task. But, at the same time, we love it and we love what we have and we feel...our whole story is like being blessed from God." (3-1)

As the father above states, having a child may be utterly life altering, but the benefits of fatherhood for these men far outweigh the struggles and challenges. Prior to having children, many of the men could not predict how their lives would change. After having children, these same fathers could not imagine life without their children. 
In addition to representing an opportunity for personal growth, becoming a father for some men was described not only as the best thing they had ever done, but also the thing in their lives of which they were most proud.

"Well, I think the issue of being a dad to me was definitely the foremost thing in my mind all the time. More so than anything else I do. It's more than being a doctor. It's more than being gay. All throughout the day I think of them even though I am at work, I think of them, if there's anything we're planning on doing, I think of them. So, definitely for me, fatherhood is the foremost thing on my mind all day long...more than any other identity that I have." (1-1)

"there are so many situations where he just rocks your world. I was working and doing stuff and he just sat there beside me and I was holding him while I was playing on the computer and it's just incredible. I mean, there are so many moments like that where it's just phenomenal. But there are little vignettes when you are sitting there rocking and where he falls asleep or you're shopping and he falls asleep in the baby carriage or you're talking to him and he's explaining stuff to you and stuff like that." (2-1)

"The best part is I'm just seeing him do things for the first time and he wakes up really, really well and you go in the bedroom and open the blinds and he smiles and that's a great thing. So those are the two best of worlds..." (2-2)

For many heterosexual couples, the transition to parenthood represents a somewhat expected and socially supported stage in one's life. For gay men, however, this life stage is one which is only recently becoming available to them. As these men so eloquently state, they are gaining great personal rewards through their experience of fatherhood.

In addition to the ways in which parenthood affects each member of the dyad individually, parenthood also has both positive and negative effects on the relationship between the partners.

“...having a child is good for a relationship...cause it kind of breaks all the rust away and you have to re-conceive of what it is and...we seem to be changing more now, constantly, which is, I think a good change." (2-1) 
"we had some pretty amazing talks about what we don't want to do in the whole situation is lose what you had started for, which is us. We're friends. We like each other. We like doing things together. We like each other and a child coming in throws a huge bomb in the center of that..." (2-1)

"when we go out...just the two of us, we talk about (our son) and...we talk a lot about other things normally but when it's just the two of us, connecting just one on one without that third part is really a change...We hardly do anything without being in the family." (3-1)

"There is no sex. Particularly when you have your kid sleeping in your bed.

Everything we do is with (our son) now. We argue more now than we ever have. I guess I'm more self-assertive. I'm assertive now... in what I want and what I need now." (3-2)

"...you know the physical side just isn't there. It's a funny thing. Having the child there and going so long with such a decrease in the physical contact and all, it just changes your attitudes about sexual activity and all." (3-1)

“...we totally didn't even think about ourselves for that whole time (during the adoption process)... and we still can't really. We didn't go out during the whole time. So now we go out every once in a while, but it's still not..." (4-2)

"It's not about each other any more. It's definitely about him...everything that we talk about, everything that we do, has to do with being either somehow connected to him or revolves around him." (7-2)

"But we both check out each other's feelings more often now. And we didn't do that kind of touchy feeling kind of checking as much before. It's about communication. I think we communicate better now." (7-1)

Parenthood represents an important developmental milestone for any parent. In addition to the joys and opportunities for growth associated with parenting, there can also be many challenges along they way, including those that may affect each member of the dyad individually as well as those that can affect the relationship between the two parents. For same-sex couples, the additional challenges brought on by parenthood represent a new experience, as opportunities for parenthood are themselves a recent occurrence in these relationships. 


\section{Adaptive Responses to Social Forces}

A large part of reaping the rewards of parenthood involves not only meeting the challenges of becoming parents, but then continuing to meet the daily struggles of being a parent. For the families in this study, this next category identified involved facing these struggles in the context of a family unit that is not always valued and supported by others. While the families who participated in this study possess many of the attributes associated with child-rearing success (e.g. high levels of education, abundance of resources, family stability), unlike their heterosexual counterparts, they must contend with raising their children in a society that often marginalizes them and may even demonize their existence. Due to this unfortunate reality, systems of support and methods of responding to overt and implicit attacks can be extremely important to the psychological health of both parents and children.

The fathers interviewed in the current study are often faced with the task of acknowledging their difference from other families. In order to mitigate the negative effects of societal disapproval, these men often find themselves in the role of educator when responding to questions about their family constellations. By doing so in an open and honest manner, they in turn teach their children the value of honesty and pride in one's family.

'I'll do it again when it's appropriate...if I'm in a rush and I don't have time to deal with it...I'm not going to divulge my personal life to them. But, if the condition where someone's asking... and I have the moment to answer correctly, not blow them off...I would answer it." (2-2)

"But there's a whole level of disclosure...there's a whole body of information that says that they (children) subtly get information from people around them and you have to understand what they're hearing when you deny or you don't...." (2-1)

"...we cannot deny the fact we're gay men and be the least bit embarrassed of it any longer...I know that we all have that tendency...to be homophobic ourselves 
... It's an internal struggle to deal with ourselves as well as him and we have to deal with it for his sake and ours." (2-2)

“...we were talking about our kids and...the first thing she said was, 'So, the biological...parents haven't called you about him yet?' I say, we're the parents, remember... why do you keep asking that every time we talk about (our son)?

...finally, I had to confront her and say what about me? This is my child. It took her a while to accept that..." (3-2)

“...his school had always celebrated just Mother's Day...so they never had anything for the dads. We had voiced our concern, and the woman who runs it said, 'Well, you know one of you guys can come, you know, it's not a big deal.' And they weren't getting...how it was affecting him. There should just be a Parents' Day, because I mean you also have single parents there... and how it's going to affect kids... and making them feel excluded. So I went, and then afterwards, she came up to me, and she was practically crying. She said, 'Last night I finally got it. I understand what you guys are talking about.' Next year we'll just have Parents' Day.” (4-1)

".... a situation a couple of times has happened to me...parents would say...he must look like his mother and...I always tell them he's adopted, so me and my partner are very happy with that." (7-2)

"One thing that I'm very aware of is people see us out there together and...people sometimes come up and say oh, what a beautiful baby...and they invariably turn to me and ask if he's mine...It's almost like a dis-acknowledgement of the fact that we might be a couple. But you know, we set them straight most of the time." $(7-1)$

Often, the role as educator is a necessary though not always welcome task. As illustrated in the quotes above, the manner in which this role is carried out can range from somewhat confrontational to subtle in nature.

Some of the men in this study, because of the age of their children, had not yet faced the task of talking to their child(ren) about their unique family. However, for those men with older children, many were faced with the task of discussing or explaining their unique family characteristics. While the parents of any adopted child may have to deal with questions from the child such as "Where did I come from?" for two gay men raising 
a child, such questions may require more thought and sensitivity with regards to the answers.

“(Our son) already asks 'Where is my mother? Everyone else has a mother.' And, we just said 'Well, you have a mother. Her name is Laura and she lives in Key West.' And that's the end of it."(1-2)

“So if you say 'oh, you know you've got two daddies.' He's like 'Robbie has two daddies too.' And when they kind of apply it to something else they already know it seems to click and make sense. So it is something that he can definitely identify with...I don't think it's going to be some serious sit down discussion. I think it's just the type of thing that when they ask questions, we just answer them. $(1-1)$

Well, we have a book by Jamie Lee Curtis and it's been waiting to be read...so I think we're gonna start that way...so we're slowly reading stories about stuff like that. It's easier for him to accept it when it's coming from a story..." (3-2)

"...we take it as far as he wants to take it at that time in an open way but we haven't pushed it. We haven't pushed it also because we find it a threatening subject... we see ourselves as such a normal family that...we forget that we're not. (3-1)

"...we have a whole story about the night he was born, when we picked him up at the hospital... and then we went to see the judge and...made us an official family, even though we were a family before, we were made official by the court...That was our "Gotcha Day" that we celebrate." (4-1)

"He knows that there's just different families. There're some families with two dads, some families with a mom and dad, some families with two moms, some families with just a mom or just a dad." (4-1)

The fathers who have begun to talk to their children about their unique families display a desire to do so honestly and openly coupled with an understanding of the child's needs. As one father put it, having to discuss the topic can be an unwelcome reminder that these families are outside of the realm of "normal" family compositions.

Sometimes, the fathers are confronted with public disapproval (both experienced and merely feared) and the need to shield their children from such behavior. Some 
parents report a sense of having to maintain a certain level of vigilance to protect the family.

“...every now and then we've felt husbands, other fathers never really warming up to us. And they're usually fathers from Oklahoma or from Texas coming down to Mexico for vacation. But that's the only time we've ever felt a little bit like...hmm, what's wrong with him?" (1-2)

“And I'm sure there's people that object. But I think those people just don't say anything. " (1-1)

"There were the four of us and this realtor said, 'Oh, so you guys are all together?' When we were leaving he said, 'Well, you make sure to tell your spouses what a nice house this was.' It's like, it makes more sense to you that we're two straight men with our kids without our wives looking for a house on a Sunday afternoon with our wives at home watching the football game? In his mind that made more sense than the fact that we could actually be a family." (1-1)

“...we've had more in the last month or two responses from the straight world to us having (our son) and, I don't know why, but more negative feedback than I had expected." (2-2)

“...we had some problems recently with people saying they don't like the idea of us having kids but (our friend) asking around some of her friends. Some of the friends were appalled or surprised and concerned." (2-2)

“...people watch us a lot more...we don't specifically know what they're thinking but they're certainly thinking something because they're looking a lot harder than they used to." (2-1)

"...the way we get stares in restaurants sometimes...maybe a little bit more like...empathy for the child like this isn't good for the child." (3-1)

"We get that if you travel out of the country, you're scared to travel out of the country to Mexico and to Canada and both times there were mild disruptions... here we are the two parents, our names are on the birth certificate, (our son) having his own passport and the agent saying where is the letter from the mother giving you permission to take the child out of the country? It's a real shock that someone is questioning our authority." (3-1)

His partner concurs stating:

"So we have to carry proof that he is our child...They have accepted it except little comments like the one in Canada where... They pulled us out of the 
line...And actually took us to the side where they search other people but in our case it was more like 'Why is there no mother?' and we even get a comment where the one guy said...I said, oh, he doesn't have a mother and we're his parents. And he says, 'Everybody has a mother.'... we just show the birth certificate and the passport but we bring the affidavit from the judge, just in case. So, we have to carry all that stuff." (3-2)

"But I still carry the adoption paper with me in my wallet just in case I'm ever stopped. And we still get, when we're going to LA, these freakish towns between here and LA, if we stopped at a Denny's and take him to the bathroom, there's always people staring at us, like what are they doing?" (4-2)

"Yeah, I mean, their ignorance, I guess, and most of them just, you know, they give you the look..." (7-2)

As these quotes suggest, there is a pervasive social belief that there is something fundamentally wrong with two gay men parenting a child. For many of the men, even though their adoptions have been finalized in court, there is still a sense of fear concerning the permanence of the custody of their child. As evidenced above, there is often a valid need to remain vigilant, especially when traveling outside the relative safe surroundings of the San Francisco Bay Area.

In an effort to deal with public disapproval, some men also spoke of the need to protect their children from negative reactions. Some parents employed a "personal barometer" in dealing with public scrutiny and comment; confronting negative reactions when necessary, and shielding their children from harmful comments.

“...if you're at all certain about not wanting to come out of the closet, don't have kids cause you're going to be outed every single day...that's important because he doesn't need, on top of the fact that he is adopted...he doesn't need all kinds of other messages too." (2-1)

“...if you don't want to take your kid into this situation because you think it will be damaging, don't take yourself in that situation, either...but let's not focus on those things that are out to damage us. Let's focus on all the good stuff and not be hidebound by society saying you can or can't do that. Let's not buy into that..." (2-1) 
"you have to realize when you're with your child...that your child is not an instrument of political agenda. You have the first responsibility to your child, and if that means even to get out of a difficult situation... it's easier to just be polite and move on than to make a point." (7-1)

As these quotes indicate, these men are often faced with the decision of when and how to respond to individual comments and criticism about their families. The manner in which they react to other's questions and comments can play a vital role in helping their children to develop a sense of family pride.

"One of the things that I think is really important to think about when you're in a situation like this...is don't take on other people's phobias because I've always felt...it's not about me. We don't know what other people are thinking. And it doesn't really matter. So let them deal with their own stuff...We have enough to deal with here. So let's focus on that." (2-1)

"We take him to the park, where we even marched two years ago with the All Our Families coalition." (4-1)

For all of the couples interviewed, there was the recognition that they had created their families despite the complexities and the roadblocks along the way. However, once the child has joined the family, there is the ongoing struggle to deal with occasional social disapproval, the need to protect the child, and a need to be prepared for an often uncertain future.

\section{Visibility and Social Activism}

While few of the men interviewed explicitly identified "activism" as a major theme, the category of visibility and social activism is nonetheless a very salient topic for these men and their families. Though their level of involvement in a "gay movement" varied across participants, all of the men did acknowledge that they had overcome great odds in forming their families. Often, they also found themselves playing the role of "Gay Dad Spokesperson" both in the gay community and in the larger society. Finally, many of the men spoke of a sense that gay and lesbian families are gaining broader 
recognition and that society is slowly becoming more accepting of gay and lesbian headed families.

Forming a family through adoption can be a difficult process no matter the sexual orientation of the parents. However, for these two father families, the hurdles with which they must contend can bestow a sense of having surmounted great social and legal obstacles. For some of these families, they have set a precedent through their success in forming their families, effectively becoming pioneers in this new social phenomenon.

"And then that started a huge legal battle." (4-1)

"We ended up finding more out about the whole process in about two weeks, three weeks, than the county knew. And, unfortunately, at the beginning...not knowing how the system worked, we were very vocal about things and what should be happening, which the county didn't like." (4-1)

"So we were the first family to ever fight the county and win. Nobody had ever beat the county before." (4-1)

While all of the families in the current study completed their adoptions within the relatively supportive San Francisco Bay Area, nonetheless, some families still had to contend with legal obstacles along the way. The likelihood of less accepting family court judges and adoption workers in other areas of the country severely limits the possibility of adoption for other same-sex couples.

The men interviewed for this study did not necessarily describe themselves as social or political activists, but they all had a sense of being pioneers in heretoforeuncharted territory. As such, they represent a new generation of gay fathers and an important part of an evolving social phenomenon.

"We kind of realized that there's no one doing this...So, when we were doing it, it was something that really wasn't done." (1-2)

"Even in this area...it was all pretty much lesbians and even a lot of the fathering groups were guys that were married and came out later." (1-1) 
"... and so it all came back to one other couple who had done this and so there really was not a lot of history there for us to follow." (1-1)

"It was a real concept when somebody called me a pioneer. I never thought of myself as a pioneer..."(2-1)

Only recently has the struggle of gay and lesbian headed families gained media attention. The majority of these men knew few, if any, other gay male couples who had successfully adopted. While they may not have thought of themselves as pioneers, these men were forging an important path into an unknown area.

Due to their "novelty status" whenever they are identified in public, these gay fathers and their families often find themselves acting as "spokespersons" in the gay community. Strangers often approach them out of curiosity or sometimes to inquire about the process by which they formed their families.

there's other gay men that have always been kind of interested and have a lot of questions about the process and all that. (1-1)

Like if we walk in the Castro, everybody knows it's (our son), 'Oh, (son's name)...' But that was not the case at first... we had dragged so many people into this adoption just to get him that now everybody feels a little responsible for us having him, and that's fine." (4-1)

"...these two women stopped us on the street and said, 'We saw you guys walking, you know, with your baby, but one of you had him in that direction, and the other one has him now. She says who's the father?' and we said 'We both are...' And they were like, 'Oh, right on...' and they asked to take our pictures." $(7-1)$

"We had guys come to us...I heard the one say to his partner, 'I have to go talk to them' and he came over and, you know, he started right away like engaging (our son) and everything, and then very subtly started asking us questions, you know, about did we adopt and all that stuff, and we started talking to him, and then he confided in us that him and his partner were just starting their process... so it's also good to be there and be supportive of other people" (7-1)

Undoubtedly, two men with a baby are going to invite both negative and positive attention from passers-by. As was discussed earlier, some of the negative reactions come 
from within the gay community. However, as social attitudes change and as more gay couples think about having children, this "first wave" of gay fathers is going to find themselves in a "spokesperson" role on an increasing basis.

Fortunately, despite the long and difficult process often associated with the adoption process, many of these fathers report a newfound sense of satisfaction, sensing that society may be changing and slowly becoming more accepting of gay parents.

"I think in terms of any preschool that you can think of in the city, none of them are not going to be accepting to gay parents. It wasn't going to be an issue no matter where we looked. And I think I even brought it up there and they were like, 'We have so many mixed family combinations so don't even worry about it. It won't even be an issue'." (1-1)

"It's going to work to our advantage to be gay dads because a lot of these schools are looking for diversity. So, you know, they like to have gay families, especially gay dads." (1-1)

“...everyone's coupled down, settled down, we're living our lives, going to jobs. No one goes out partying weeknights. We have dinner parties. It's a very kind of sedate life that has room in it for more children..." (2-2)

"The feel in the community is that as more and more people come across it, it's more people that are saying, 'Wait a second, what about that?' And that's where we came from." (3-1)

"...but there's more and more strollers in the Castro now. Yeah, definitely a lot more strollers, and a lot more people that are more accepting..."(7-2)

As the numbers of gay and lesbian headed families increase and as these families become more visible, there is the hope for increasing social acceptance and support. While there is likely a long road ahead in terms of legal and political support, fortunately these fathers report subtle but noticeable changes within their own communities.

As the previous sections illustrate, adoption can be a long and difficult process for some families. For many prospective gay fathers in particular, there can be lengthy legal battles along the way. Systems of support, including supportive family members and a 
network of role models and good information sources, can be particularly helpful during these difficult times. In addition, the development of adaptive behaviors, such as educating others through positive social interactions and modeling openness and family pride can also mitigate possible harmful effects on the family. These issues will be discussed in greater detail in the following chapter.

When all of the categories and concepts discussed throughout this chapter are put together, they provide a narrative of the process of two gay men, living as a couple, and creating a family through adoption. Their process is unique because they are forging new ground by expanding the socially proscribed roles for what gay men, men in general, and fathers are expected to fulfill. The manner in which they create their families includes demanding access to and navigating the often difficult world of public and private adoption. Much like all families, their success is interwoven with the available systems of support provided by family, friends and the community within which they reside. Finally, their very success in creating families as well as the ongoing development of their families has a transformative effect not only on the men themselves, but also holds the potential to transform the social ideals of what constitutes a family and what roles fathers play within these families. This act of living as a visible family unit, often subtle in nature, makes these couples and families social activists in this new social phenomenon. This rich narrative is discussed in Chapter Five as part of a theoretical model, which attempts to capture the development of these families. An important part of this model, also discussed in the subsequent chapter, is the social context within which this phenomenon is embedded.

\section{AN EMERGING THEORY}

A precursory examination of the data from the interviews would seem to indicate that these men are not really that different from anyone desiring to have children. On one 
level, this is an expected, albeit not very exciting finding. However, in order to truly grasp the significance of the act of parenthood for these men, one must examine the social and cultural milieu within which the formation of their families takes place. As will be more fully discussed in the following chapter, as the data were analyzed, a rich narrative unfolded, detailing a process of struggle, change, and reward. For these men, the very act of choosing to form families in the face of prevalent societal attitudes makes this new generation of gay fathers both pioneers and activists. They are forging new ground and fighting a long-standing dominant paradigm that prohibits men from parenting without a woman to fulfill the role of "nurturer." Despite social and legal proscriptions against gay men as parents, the men in this study are creating families and thriving in the face of adversity. For their struggles, they are reaping rewards that were heretofore reserved only for married heterosexual couples. The implications of these findings will be presented and discussed along with a theoretical model that attempts to capture the richness of this new family experience. 


\section{CHAPTER 5}

\section{Discussion}

When analyzing data from a grounded theory approach, the final step involves formulating a theoretical model to provide a logical, systematic, and explanatory scheme to explain the immense amount of rich data collected (Strauss \& Corbin, 1998). This chapter brings together the data from the previous chapter and introduces a model for interpreting the data and proposing new theory. As the data are interpreted from a grounded theory approach, the model provides a means to describe and "make meaning" of the new social phenomenon. Results from comparable studies with similar samples of gay fathers are also integrated in relation to the findings in the present study.

A visual representation of the theory derived from data presented in the previous chapter is presented in Figure 1. As depicted in the diagram, each father's identity consists of at least three seemingly, but not necessarily, incongruous identities (gay, male, and father). While earlier research (e.g. Bozett, 1989) tended to focus on each identity separately and the task for each father of integrating them, results of the current study suggest that these identities are not so much separate as much as they are part of the multi-faceted identity of each father (this multi-faceted identity is represented by the overlapping circles).

It is also important to consider socio-political and socio-cultural factors when discussing families comprised of two gay men and their adopted children. There are many negative socio-cultural messages concerning each of the three identities previously mentioned, especially where infants are concerned. As such, each father (and each family) faces the challenge of contending with the negative social messages propagated in the dominant culture (represented by the arrows at the top of the diagram). 
These fathers have created their families through the process of adoption and will likely continue to address issues associated with being a family of adoption. They are also likely to face the ongoing developmental task of adapting to the challenges of being marginalized families. For a large part of American society, these families continue to be outside of the "norm."

Despite the challenges they face, this new generation of gay fathers exhibit strength and resiliency in constructing and raising their families. Due in no small part to their ability to face challenges and thrive in the face of adversity, these men are themselves transformed while at the same time acting as forces of change to transform the very idea of fatherhood in American culture. One major contributing factor in their ability to thrive is likely related to the socio-cultural context within which they live. The positive social milieu of the Bay Area (including class and privilege) is represented by the upward pointing arrows at the bottom of the model. The parts and whole of the model are further explained in the sections that follow. 
Model of Gay Father Development

\section{Negative Socio-cultural Messages about Gay Men} and Men's Ability to Nurture an Infant
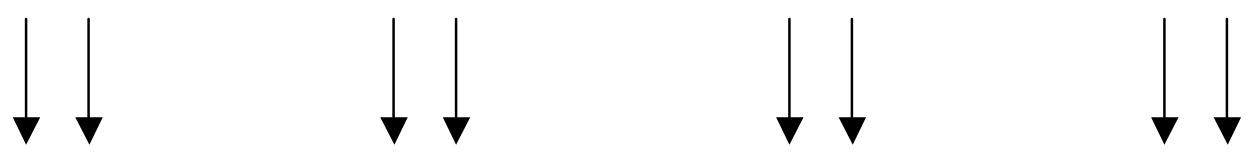

Forging New Ground Creating a Family Transformation
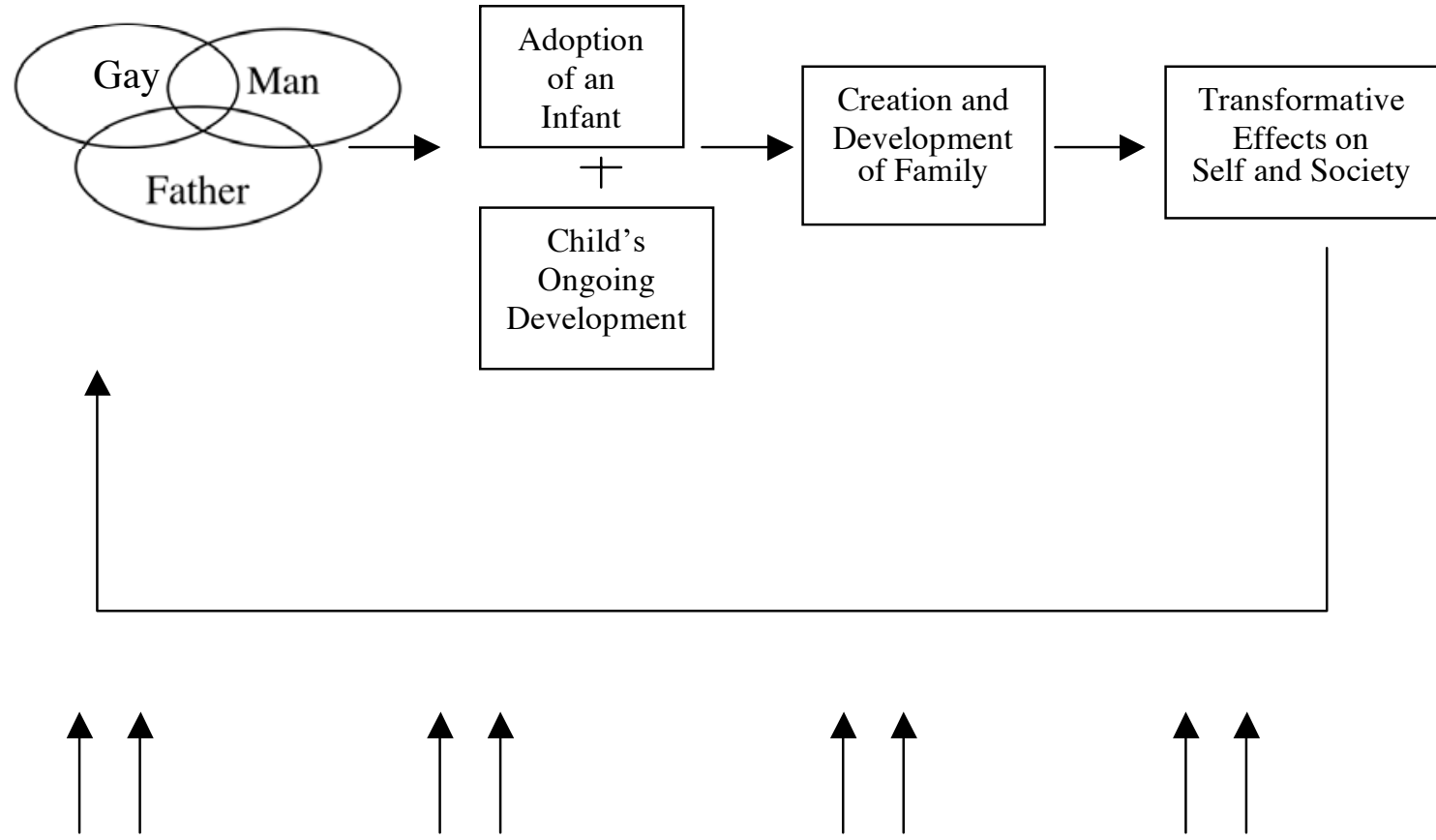

Positive Socio-cultural Context of the Bay Area and Influence of High SES and Privilege 


\section{Negative Socio-cultural Messages}

One does not have to delve too far into popular and pseudo-scientific literature to find a myriad of myths concerning gay men and children. For example, some widely held beliefs include: gay men are not manly; gay men are weak; and gay men are effeminate. Related to children, gay men are misconstrued at being uninterested in children at the very least, and demonized as being unfit to parent and a danger to children in the most gross forms of social prejudice (Bigner \& Jacobsen, 1989; Patterson, 1992). Aside from the myth that gay men are more likely to molest a child in their home, other beliefs are that children placed in a home with gay parents might turn out to be gay or that gay men are not suitable role models for children (Mallon, 2004). Apart from the assumption that gay men aren't supposed to want children, gay relationships are stereotyped as lacking stability and of short duration and therefore not suitable environments for raising children. As Terry Boggis, director of Center Kids, a program of the Lesbian, Gay, Bisexual, and Transgender Community Center in Manhattan states, "There are so many damaging messages that gay men have heard all of their lives about why they can't be parents or can't be involved with children, so it takes a little longer to come around and believe that they could be good at it" (Mallon, 2002, p. 71).

In addition, there are also many negative socio-cultural beliefs about men and their ability to nurture children. For example, it is presumed that men are generally not motivated to have children out of a need or desire to parent. In popular culture, one does not speak of a "paternal pull" in the same way one might mention a "maternal pull" to have children. Likewise, a man's biological clock is not presumed to get louder as he approaches middle age without having procreated. Furthermore, men generally are not characterized as having the nurturing qualities deemed necessary to care for infants. Indeed, men are presumed to lack certain nurturing qualities that are generally attributed 
to women. Women, on the other hand, are presumed to possess natural abilities related to nurturing and caring for an infant.

The men in this study are in the unique position of being primary caregivers to infant children; a realm largely populated by mothers. These primary caregiving fathers (PCGF's) would likely fit well into this culture of mothers and their infant children and may naturally gravitate toward this group. However, many of the men in the current study report feeling excluded or even ostracized when they found themselves to be the singular male in a situation dominated by mothers. For example, one father spoke of feeling isolated while at the park with his toddler and failing to gain entry into the various social groups of mothers at the park with their children. Instead of being seen as an "insider" this father was kept on the outskirts of the group. Despite repeated visits to the park, he continued to be viewed as an oddity. In addition, one participant in Mallon's (2004) study reported "I have seen the way gay men have been challenged in this new parenting role. It's just a female, mommy-driven culture....And the lack of welcome for gay men...has got to be painful and extra challenging and extra scary" (p. 69).

In addition, many of the men in the current study spoke of receiving unwelcome advice from women while out in public. In his study of single and coupled gay fathers, Mallon (2004) writes that the men in his sample attribute such unwelcome advice to a sense of competitiveness on the part of the women, indicating that the women do not want to share what has typically been their sole domain. While the input from these women may be well-intentioned, some gay fathers may experience this input as "fundamentally gender based, a blatant case of reverse sexism" (Mallon, 2004). In addition, Martin (1993) wrote that when gay men with older children were out in public, women assumed they were "helping mom out." However, gay men with infant children were often met with hostility by women who presumably believed these men to be unable 
to provide care for an infant child. Unfortunately, the exclusion of gay fathers from the "mommy culture" likely cuts the men off from a possible source of social support. At the very least, new mothers likely learn important parenting skills through interaction with groups of other mothers. More importantly, such groups also serve to provide important emotional support in adjusting to the new and constant demands of parenting an infant. These negative messages and the challenge they present to the fathers in the current study are further examined in the following sections on the multifaceted nature of gay father identity.

\section{Multi-faceted Identities}

As depicted in Figure 1, every gay father has at least three seemingly distinct identities that contribute to his overall self-image. While one can easily argue for many other identities (e.g. ethnic, professional, religious, etc.), for the purposes of this discussion the focus is on his identity as a man, his gay identity, and his identity as a father as well as how each of these identities overlap.

Some men may integrate these separate identities with little effort or awareness on their part. However, it is important to consider the often covert challenges imposed on these men in our current political and cultural climate. While it is tempting to consider these different pieces of each man's identity, it is also important to consider that we truly are more than just the sum of our parts. For each man, to just consider his "gay" identity or his "father" identity would be to oversimplify the complexity of human beings and the unique characteristics of each. However, for the purpose of this discussion, each piece initially is discussed independently. 


\section{Gay Identity}

All gay men are faced with the challenge of developing a healthy self-image despite the negative messages they receive from a variety of sources in American culture. Despite recent advances in social attitudes about gay people, many myths abound as evidenced in the discussion above. Additionally, gay men also receive subtle and not so subtle messages about parenting from within the gay community or gay culture. As one father in Mallon's (2002) study states, “...the reaction from mostly gay men was pretty negative...it was usually like 'What are you trying to do? Be straight people?'” (p. 88). Although attitudes are changing with the increasing visibility of gay fathers, gay men with children have generally been relegated to the fringes of the gay community. Until

recently, there was no place for gay male fathers in a world often organized around typically adult activities. Just as early gay activists were instrumental in changing social attitudes about gay people, these gay fathers represent a new type of gay activist. These men are changing society's concepts about gay people as well as changing attitudes within the gay community.

\section{Man Identity}

Every man, whether gay or not has internalized to some degree the ideals about what it means to be a man in American society. Generally, these ideals dictate some degree of stoicism and emotional detachment or aloofness. Men are expected to be strong, sometimes hyper-masculine, as well as career driven; even valuing career over family. According to social role theory, men are expected to exhibit agentic qualities (i.e. focus on self and autonomy) and women are expected to fulfill the feminine gender role of communal qualities (i.e. focus on other people and relationships) (Wood \& Eagly, 2002). Men and women who violate social norms concerning appropriate gender role behavior are likely to experience social disapproval (Harrison \& Lynch, 2005). Related to 
the fathers in the current study, many are violating the social norm for being career focused as opposed to family focused. Many more are violating norms concerning men's motivation to be the primary caregiver to an infant child. According to social role theory, these fathers can expect to experience much social disapproval for engaging in gender atypical behavior. Moreover, due to experiences with both real and imagined rejection or abuse, gay men may be at risk of being forced to become even more autonomous, stoic and independent out of fear of rejection (Greenan \& Tunnell, 2003).

For the men in the current study, each has had to transcend the strongly held beliefs about what men are thought to be and what they are assumed to want. Doing so has enabled them to take on roles traditionally associated with women, that is nurturing and "mothering" an infant. As will be discussed further in a later section, by eschewing traditional gender roles, these men are expanding the concepts of "father" and "caregiver."

\section{Father Identity}

Finally, all men, whether fathers or not, hold socially constructed beliefs about what it means to be a father. In American culture and much of Western society, fatherhood has meant taking a secondary role in childrearing. Generally, a father's most important task is to provide financial stability for his family. Infancy is conceived as the realm of mothers, with fathers thought to lack the desire, or even the ability, to nurture infants and young children. In popular media, fathers are typically portrayed as "awkward, clumsy, and uncomfortable in the role of nurturer" (Mallon, 2004). If fathers are described as playing a larger role in their children's lives, it is usually during the period of adolescence and often involves the role of family disciplinarian. There are very few examples of fathers taking on the role of the primary caregiver in their young 
children's lives. In fact, fathers in public with young children often attract unwelcome attention. As one father in Mallon's (2002) states,

"A man with an infant (forget gay or not gay) is a very uncommon sight in American society. While a woman with a baby engenders almost immediate social contact - baby as social lubricant if you will - a man with a baby, especially an infant, engenders suspicion....it's almost as if a man is deemed incapable of caring for a baby...Most women are also ipso facto assumed to be competent caregivers; men are almost assumed to be the exact opposite, solely based on their gender" (p. 70).

Certainly, current Western social ideals of fathers do not include gay men. Not only are the fathers in the current study playing a larger role in the lives of their children, they are demonstrating that fathers truly can play the role of primary caregiver. However, due to the fact that they are violating many social norms by caring for their infant children without the aid of a woman, the fathers in the current study are likely to continue to experience social disapproval much like the father quoted above. While these fathers are acting as agents of change by challenging long-held beliefs about gay men and fathers, the battle to transform such socially constructed beliefs is likely to be longlasting.

\section{The Whole is Greater than the Sum}

As stated previously, it is tempting to focus on the task for each father to integrate these seemingly distinct identities. In fact, as earlier research has suggested, identity integration was likely a salient challenge for earlier groups or cohorts of gay fathers (Bozett, 1989). However, it is important to distinguish between the research participants from earlier studies and those from the current study. Past research tended to focus on men who had become fathers through heterosexual unions (usually marriage) and had later come to recognize their homosexual identities. As such, identity integration was likely a very salient and difficult task for these men. Therefore, it would be expected for 
research to show that this earlier generation of gay fathers struggled with such questions as Am I a father or am I a gay man? These men often also struggled with whether to or how to come out to their children and/or their wives.

For the new generation of gay fathers represented in the current study, identity integration does not appear to emerge as a significant task. The majority of these men had already come to terms with their sexual identity and spent many years "out" in the gay community prior to becoming fathers. In addition, the current study took place in the San Francisco Bay Area; an area that is known to be welcoming and accepting of gay and lesbian people. As Figure 1 depicts, "Gay," "Man," and "Father" are not such distinct and separate identities. These identities are merely three labels that contribute to each fathers overall identity. Rather than focus on how each of these identities is separate, a focus on the overlap of these identities may yield more important findings about fathers in general and about primary caregiving fathers in particular. The struggle for these fathers then, is to fit into a social structure that does not embrace or acknowledge families headed by same-sex parents. While each family is unique, the one commonality across all gay fathers is that they violate two major social norms: gay men cannot be trusted around children and men cannot be the primary caregivers and nurturers of children (Mallon, 2004).

\section{Creating a Family}

Gay men and lesbians have children and create families in a multitude of ways. Both may have children from previous heterosexual unions. Lesbians may choose artificial insemination or co-parenting arrangements with a male friend. Gay men and lesbians may also create families by entering the foster care system or choosing to adopt. As Melina (1998) points out, gay men are vastly different from the majority of heterosexual couples who choose to adopt, and thus in a unique position with respect to 
adoption. Whereas most heterosexual couples come to the decision to adopt when all other attempts to have children have failed, gay men often pursue adoption first as the means to creating a family. While heterosexual couples may arrive at the decision to adopt from a place of loss and are often encouraged to mourn the loss of the child they never had, gay male couples may approach adoption with excitement and anticipation as a means to achieving the children and family they thought they would never have. While we need to be cautious about exaggerating the positive aspects of adoption by gay fathers, there seems to be a growing sentiment that gay fathers are truly in a unique position when it comes to raising children. As one father states, "I think we take parenting more seriously. We had to go through a little bit more to do it, thought about it a little bit more...I think adoptive parents and gay parents tend to think more about parenting" (Mallon, 2004, p. 73). On a related note, the American Academy of Pediatrics released a statement on February 4, 2002 endorsing adoption rights for gay and lesbian parents. One of it's members, Ken Haller, M.D. of Missouri states, referring to same-sex parents within his practice,

"They are like all parents in wanting the very best for their children. But because there are often societal obstacles to their relationships and to gay parenting, there is a level of commitment that you don't always see in opposite-sex parents. When gay people have kids, it's truly a choice, and it's sad to say that's not always the case with [straight] parents" (Bull, 2002, p. 20).

While adoption offers an exciting opportunity to gay men, it is also a system fraught with challenges and imperfect practices (Mallon, 2004). As discussed in the previous chapter, becoming parents through adoption can be an emotionally and financially exhausting process and often requires hours of research and planning. While it is important to be educated about and prepared for the legal difficulties, it is equally as important to choose a good lawyer. As one father from Mallon's (2004) study states, “...this process is so complicated and so bureaucratic, no wonder why people don't 
pursue the adoption process---it's a jumble" (p. 48). Once deciding on adoption as the means to parenthood, couples must then contend with orientation meetings, home studies, providing personal references, financial disclosures, and medical reports, not to mention the unknown variable of exactly how long the whole process will take.

Once the child actually arrives in the parents' lives, the process shifts from creating a family to being a family. This shift results in many changes, including how the parents relate to their own parents and extended family members, how the parents relate to one another, and any ongoing relationship there may be to the birth mother or the child's family of origin. Any parent will attest that every aspect of one's life changes when one becomes a parent. As one father succinctly states, "Our house changed, our relationship changed, our relationship to our jobs, friends, and families changed. The way we shopped, spent money, exercised, and socialized also changed dramatically--everything changed" (Mallon, 2004, p. 67). It is important to note that these challenges are not directly related to the fact that the two parents are gay men, but rather are common to all new parents. The difference lies in the fact that the majority of heterosexual couples who are new parents are socially sanctioned as a family form and therefore receive a certain amount of familial and social support. There are role models, books, training programs, and magazines available to offer support and advice. The amazing thing about the success of gay fathers is that they are creating and nurturing their families within a broader social context that doubts and often denies their ability to do so.

\section{Family Development}

Due in large part to having lived their lives as members of a disenfranchised minority group, these gay fathers have developed admirable strength and resiliency in order to deal with negative social messages. Surviving, much less thriving, as a gay person in this culture often means adapting to the experiences of discrimination and 
oppression. As boys, gay men experience unreceptive and even hostile environments at school, in the community, and often at home (Lasser \& Tharinger, 1997). All gay men likely know what it is like to be called "sissy, faggot, and queer." For many of the men in the current study, they also survived the early AIDS crisis of the 1980s. Such experiences likely result not only in resilience, but also in forced determination to achieve what one feels one is entitled to. In the case of these fathers, this includes the right to parent. This strength allows them to thrive in the face of adversity while also modeling effective coping strategies for their children.

Despite the legal and social proscriptions these families face, they nonetheless exhibit incredible strength and resiliency in adapting to these challenges. In fact, having children may promote resilience by leading to the creation of more complex social support systems for the family (Oswald, 2002). For example, the mere act of having children provides a reason for parents to come into contact with others who are in similar situations. Contact with other parents of infant children may occur in doctor's offices or in playgroups. As children grow and their own social networks expand, parents come into contact with other parents through school and community activities. Siblings of the parents themselves, as well as coworkers with children, may also promote expanded support systems. In addition, many researchers have suggested that, similar to families from other marginalized groups, the families of gay men have much to teach us about "gender relationships, about parenting, about adaptation to tensions in this society, and especially about strength and resilience" (Laird, 1993, p. 284; see also Okun, 1996; Stacey \& Biblarz, 2001). The field is ripe with opportunities to study these issues in such families.

Much like ethnic minority families, the way in which gay fathers deal with discrimination can send messages to their children about how they should handle the 
often hurtful actions of others. As Boyd-Franklin (1993) writes, African-American parents strive to give their children the tools to deal with racism while simultaneously working to instill in them the belief that they can achieve and overcome the barriers of racism. Similarly, gay fathers find that they must act in ways to instill a sense of pride in their children concerning their families and their family history. While the children of gay parents are unlikely themselves to be gay, it is nonetheless very important for gay parents to provide their children with the tools to manage the conflicting messages they will encounter in society.

As the dialogue between one couple demonstrates, it is an ongoing task for these families.

“...we cannot deny the fact that we're gay men and be the least bit embarrassed of it any longer...It's an internal struggle to deal with ourselves as well as him and we have to deal with it for his sake and ours." (2-2)

“...if you're at all certain about not wanting to come out of the closet, don't have kids cause you're going to be outed every single day. And that's important because he doesn't need, on top of the fact that he is adopted and there's a whole bunch of messages going out about that...He doesn't need all kinds of other messages too. So, we just need to be honest." (2-1)

While the son of the above fathers was an infant at the time of the interview, nonetheless the two men were acutely aware of how their responses to societal reactions to their families can possibly affect their child.

Finally, it is important to note that adoption is not merely a singular event by which a prospective parent attains a child. Rather, it is more correctly construed as a lifelong process, not only for the child, but also for the adoptive parents. One might also consider the long-term processes for the birth parents as well. In the case of many of the families in the current study, they continue to maintain some type of communication or connection. Some families have telephone contact with either the birth mother or with the 
child's biological grandparents. Other families maintain visitation with the birth mother. While the focus of the current study was not solely on the adoption process, future research will need to examine how the life-long developmental process of adoption plays out in these families. For example, will these children differ from adopted children of heterosexual couples on measures of emotional development? Will these children develop unique coping strategies in order to confront societal objection to their families? Finally, what can we learn from these unique families as we continue to increase our understanding about what adoption means for each of the parties involved?

As discussed in the previous sections, gay fathers are confronted with numerous negative social attitudes not only about their sexual identities, but also about whether they are fit to be parents. In addition to these challenges, their families lack the legal and social supports afforded the relationships and families of married heterosexual couples. As evidenced in the recent national election, 11 states passed amendments to their state constitutions to include language that specifically defines marriage as a union between a man and a woman. In addition, the 1996 Defense of Marriage Act prohibits granting to same-sex couples any of the federal protections that come with marriage. A recent report by the Human Rights Campaign (2004) outlines the cost of marriage inequality to gay and lesbian headed families and their children. The report focuses on the impact of inequality on access to health care, social security and federal income taxes. To summarize, because there is no legal recognition of same-sex relationships in the vast majority of states and because second-parent adoption by a same-sex partner is available in only eight states, the children in these families lack the basic protections afforded the children of heterosexual parents. For example, they may not be eligible for employersponsored health insurance and they may be ineligible to collect Social Security survivor benefits if the deceased parent was not able to legally adopt the child. In addition, federal 
income tax laws are skewed against same-sex couples if one parent does not work outside of the home, so that these families end up paying more taxes than their heterosexual counterparts.

\section{Transformation}

We're halfway there. We've begun to raise our daughters more like sons so now, women are whole people. But fewer of us have the courage to raise our sons more like daughters. Yet until men raise children as much as women do and are raised to raise children, whether or not [they] become fathers they will have a far harder time developing in themselves those human qualities that are wrongly called "feminine" but are really those necessary to raise children: empathy, flexibility, patience, compassion, and the ability to let go. - Gloria Steinem, Smith College commencement address, 1993 (as quoted in Mallon, 2004, p. 131.)

As the above quote so eloquently states, few men are raised to be nurturing and fewer still actively choose the role of primary caregiver to their children. As Silverstein (2002) asserts in her research, asking men to redefine fathering as nurturing rather than providing essentially asks fathers to violate current cultural norms. However, this author asserts that the fathers in the current study are quite accustomed to violating the norms of the dominant culture. Whereas Silverstein (2002) speaks of the need for a "facilitating ideology" to enable heterosexual men to adopt these new behaviors, the fathers in the current study appear to have little, if any trouble engaging in the typically feminine behaviors of child rearing. In a sense, these fathers are unencumbered by gender role norms and proscriptions about atypical gender role behavior. As Mallon (2004) writes, this new generation of gay fathers has the opportunity to redefine roles and responsibilities based on strengths and skills rather than on gender. The men in the current study all made a conscious decision to father children fully aware of the fact that there would be no women present to take on the task of providing primary physical and emotional care for their infant children. Perhaps it is this "cognitive readiness" that assists these fathers in meeting the demands of primary caregiver. Findings from the current 
study provide a powerful example of the possibilities for fathers to play a much larger role in the lives of their children.

Whether fatherhood is considered from an evolutionary adaptation perspective or from a purely socialization perspective, the fathers in this study provide an excellent example of adaptation; something at which our species excels. These men have demonstrated an ability to adapt to the demands of childcare. They made the conscious, well planned decision to become fathers and subsequently adapted to the demands of raising an infant. Not only have they adapted to the physical demands of childcare, but they are also providing the level of nurturing necessary for the healthy social and emotional development of their children. These findings provide evidence for the case that all men posses the ability to take on a greater role in providing for their children.

In a recent study, Lichtanski (2004) compared adoptive gay and adoptive heterosexual fathers on measures of perception of parenting abilities, level of parental stress, style of parenting, and available social support. The two groups of fathers did not differ in terms of familiarity with the parenting role (as obtained by self-report), ability to solve parenting problems, or in parental stress. However, adoptive gay fathers were found to be more nurturing, warm, and positive toward their children. Results also suggest that the gay fathers provided stable and highly structured environments for their children and they were more consistent in limit setting. Adoptive gay fathers were also found to be more active than adoptive heterosexual fathers in social support systems, leading the author to speculate that this translated into more stable and consistent support available to the family.

Rather than merely interpreting these findings as evidence of differences between homosexual and heterosexual men (either biological or behavioral), we can interpret these findings as evidence that all men hold the ability to move beyond what is socially 
prescribed or accepted behavior for men. There is a large body of evidence that supports the idea that the biological males of most species tend to be providers as opposed to nurturers (for summaries, see Pleck, 1987, and Silverstein, 1996; also Buss, 1995). However, it is the individual differences in these studies that are often more interesting and from which we have much to learn. There is also abundant research that demonstrates the ability of fathers to be more nurturing and active in childcare. In addition to findings from the current study, Hofferth's work (as cited in Cabrera, et al. 2000) demonstrates that men who are raised by fathers involved in childcare tend themselves to take more responsibility for their own children, show more warmth, and demonstrate a tendency to monitor the behaviors and activities of their children. In addition, men who possess fewer gender-role stereotypes also tend to be more active, responsible and warm as fathers and tend to monitor their children's behavior more than do fathers who hold more rigid gender-role beliefs (Hofferth, as cited in Cabrera, et al, 2000).

Finally, as gay men, these fathers are paving the way for a new sense of acceptance for all gay men. They are claiming parenthood, the pinnacle of human development (Erikson, 1963). Gay men are claiming the approval, respect, and acceptance that the title of parent confers. In addition, while gay culture tends to value career achievement and the acquisition of goods, these gay fathers are expanding this definition to no longer be defined by work or career, but also by their role as caregiver to a child. As one father illustrates, speaking about his son, "I was holding him while I was playing on the computer and it's just incredible...there are so many moments like that where it's just phenomenal...when you are sitting there rocking and where he falls asleep or you're shopping and he falls asleep in the baby carriage or you're talking to him and he's explaining stuff to you..." (2-2) For this father, the arrival of his infant son had a 
profound effect on him. While still the primary wage earner, his role in the family also includes that of caregiver to their infant son. This duality of roles and the increased amount of time these fathers spend with their children may also have a positive influence on their child's development. Findings from the research of DeFranc and Mahalik (2002) suggest that children who have a more positive relationship with their fathers and who's fathers experience less gender role strain are themselves likely to be better parents. While these findings are correlational at best, they do suggest the possibility of promising positive outcomes for children of gay fathers. The profound transformative effect of parenthood on each father's self concept is depicted in the model by the arrow pointing back to overlapping identities. Through the act of parenting and nurturing an infant, these fathers are expanding their own beliefs about who they are and what they can do, while at the same time changing and expanding social beliefs about what gay men can do and what roles fathers can play in the family.

As mentioned in the previous chapter, the success and progress of the families in the current study has often required some level of activism on the part of the fathers. While many of the men may deny being outright activists, their very presence and visibility in the world makes them activists. As one father states,

"By the fact that we are gay with children, we are already activists. We don't set out $\{$ on $\}$ an everyday basis to be activists, but every action we participate in, whether it's going to the mall, to church, to the doctor, or wherever...we are out as gay people. A friend of mine recently said, "You are American's nightmare--this gay guy, with two kids, living in the city." It is so much of what this country doesn't want to see happening." (Mallon, P. 21)

Much criticism and guilt has been heaped upon working mothers and their contribution to the demise of the western ideal of family. Fortunately, gender role norms and expectations about women have changed. Consequently, women are expected to fulfill both the role of wage earner and mother/nurturer equally well. However, changes 
in gender role expectations for fathers lags much farther behind. As this study and others like it demonstrates, perhaps some of the critique should focus on the role of fathers in nurturing and rearing children. The fathers in the current study provide a valuable contribution to the development of a new definition of fatherhood. As our society continues to evolve and moves further away from the fantasy of a "Leave it to Beaver" or "Ozzie and Harriet" family, so too must the reality of our behaviors and attitudes change. Men must learn to embrace their ability to nurture and society must begin to value the worth of nurturing as part of the father role. One way this can be accomplished is to raise sons with emotional sensitivity, empathy, and compassion. Yet, until this behavior in men is acceptable and valued by our society, we are, as Gloria Steinem states, only halfway there.

\section{Positive Socio-Cultural Influences}

As stated earlier, all of the participants in the current sample were recruited from the San Francisco Bay Area. This area of the country represents some of the most expensive real estate in the country and therefore, some of the highest levels of socioeconomic status as well. In addition, this area contains one of the largest concentrations of gay and lesbian people in its Castro neighborhood. Seven of the ten couples interviewed for the current study lived minutes from the Castro neighborhood. As a whole, the participants in the current study represent a financially secure well-educated, and politically informed group of fathers. They were in a position to mobilize their resources and, if necessary, fight for their right to parent. Often this involved becoming well informed advocates in the court systems. As Mallon (2004) suggests, due to living in a patriarchal society, prospective gay fathers may also feel a sense of entitlement when it comes to navigating the adoption process. 
Fortunately, the participants in the current study live in a state that allows joint adoptions by gay couples and second-parent adoptions by a same-sex partner. Civil laws in the state also grant the same marital benefits to same-sex partners the state provides to heterosexual couples. However, the topics of marriage, domestic partnerships, and civil unions came up in almost every interview. Almost all couples report having had some sort of ceremony to announce their union. In addition, all had registered as domestic partners with the city and state. Such evidence indicates that the idea of marriage and the current marriage inequality in the United States is a salient issue in the minds of these fathers. Despite the numerous positive social factors in the lives of these fathers, there remains the pervasive inequality in the realm of marriage and familial recognition at the national level. It is likely that marriage inequality has an even greater effect on gay parents and their children in areas of the country with more discriminatory laws than those found in California.

To summarize, American cultural and social beliefs dictate pervasive negative messages about both gay men and their appropriateness as parents as well as men in general and their presumed inability to nurture infants and children. In addition, there are strongly held beliefs about fathers and the roles they should play within families. The fathers in the current study provide evidence of gay men who have confronted these negative beliefs and through embracing their role as caregivers to their infant children represent a new generation and a new type of father. They have created their families through the process of adoption and, as such represent a unique family constellation and a unique family developmental trajectory. Due to their pioneering efforts in this new social phenomenon, future research needs to examine how these unique features will continue to effect not only the development of the children in the families, but also the development of the individual fathers and the family as a whole. The very existence of 
these families is having a transformative effect on American society and the long-held beliefs about what gay men can do and what roles fathers can play in the lives of their young children and within the family.

\section{Research Findings with Similar Populations}

Schacher (2000) interviewed 21 gay fathers in four focus groups. The fathers were a heterogeneous sample recruited from four different U.S. urban areas. In addition, the fathers had children through a variety of methods including adoption, surrogacy, and co-parenting arrangements with lesbian couples. Schacher's findings focused on gay father's influences on "degendered" parenting roles, a reconceptualization of family, and a "reworking of traditional masculine gender ideology." While Schacher focused much more on the ideas of "role strain" and "gender role paradigm," findings from her research are consistent with those from the current study. For example, fathers in both studies discussed the idea of being "pioneers in uncharted territory" and the struggle to be the primary caregiver to infant children; a role generally dominated by women. However, fathers in the current study did not evidence symptoms of role strain. This difference is possibly due to differences between the two samples. Fathers in Schacher's study became fathers through a variety of methods, including surrogacy and co-parenting with lesbian partners. It is possible that co-parenting with a female partner correlates with greater degrees of role-strain. The current study controlled for this possible influence by requiring all participants to have adopted as a couple and excluded surrogacy and coparenting arrangements.

Brinamen (2000) interviewed 10 gay fathers, six of whom were parenting children with their partners and four that were single fathers. The men in this study also had their children through adoption, surrogacy, and co-parenting arrangements with lesbian couples. Brinamen (2000) outlined a five stage model for gay fathers choosing to become 
parents. The first three of the five stages involve the process of coming to accept and integrate a homosexual identity and develop a related sense of pride. These three stages bear close resemblance to Cass' (1984) model of homosexual identity formation. The final two stages of Brinamen's (2000) theory involve becoming aware of other gay families and the development of an identity that includes parenting. While the current study does not provide explicit support for identity development proceeding through discreet stages, there is some overlap among findings. For example, men from both studies spoke about the lack of fit between traditional gender roles and their current reality as two men with an infant. However, Brinamen (2000) focused on the father's need to resolve issues around the stereotype of gay men as feminine in order to embrace the role of primary caregiver. In contrast, the current study did not find evidence of unresolved gender issues in relation to childcare. This difference in findings could be due, in part, to major differences in the actual samples and their methods of becoming parents. Similar to Schacher (2000), Brinamen also included men who became fathers through co-parenting arrangements with a lesbian. In addition, Brinamen's sample included both single and partnered fathers.

Other authors have focused on the task of each man to integrate the seemingly disparate identities of gay man and father. For example, in his pioneering work on gay fathers, Bozett (1989) theorized that gay men who disclosed their sexual identity after becoming fathers faced the challenge of integrating the two identities of gay and father. A central task for these fathers was to develop a healthy identity that included both their sexual identity and their identity as a parent. Similarly, Silverstein (2002) and her colleagues compared two groups of gay fathers. One group had children in a heterosexual marriage and later acknowledged a gay identity and a second group had children after first establishing a gay identity. Findings from their study indicate that the men who had 
been married struggled to integrate their identity as a gay man with their identity as a father. These men also tended to have more traditional ideas about parenting roles. In contrast, the second group of men had what the researchers refer to as a deconstructed idea of parenting. These men reported that they did not believe in mothering or fathering, but instead spoke of parenting from a combined "Mommy-Daddy" perspective.

In contrast to the men in the previously mentioned studies, all of the men in the current study became fathers after disclosing their sexual identity and within the context of a committed same-sex relationship. The men in the current study are not faced with the task of "coming out" or attempting to integrate their gay identities into their existing selfimage. As evidenced in quotes from the interviews, being gay to these men is just one small part of who they are. As one father succinctly stated: "It's more than being gay. I think by the time I became a father gay was kind of a non-issue for me anyway and now it's totally a non-issue. It's like the last thing I think of because I am always thinking of them (i.e. the kids)" (1-1). In 1989, Bigner and Jacobsen wrote that a fundamental task for gay fathers was to integrate the dichotomous constructs of gay man and father. The authors purport that gay fathers were attempting to act in the two opposing roles of father and homosexual man. Perhaps in 2005, the fundamental task for gay fathers no longer involves attempting to integrate two dichotomous constructs, but the task involves demanding recognition and support as legitimate parents while changing the very ideals concerning fatherhood and contributing to a new definition of fatherhood.

\section{Implications for Future Research}

While results from the current study yield interesting insights into gay men's desires to parent and the primary caregiving abilities of these men, it also raises questions about fatherhood in general. For example, what motivates men to raise children to whom they have no biological connection? What do we have to learn from single fathers who 
are both provider and nurturer to their children? How do the overlap of the gay, man, and father identities contribute to the overall success of these men as parents?

Future research in the areas of fatherhood and father involvement needs to reexamine long held beliefs about the provider role and the nurturer role. For too long, researchers have failed to critically examine the notion that mothers are natural caregivers and that fathers are natural providers. Research tells us that neither mothers nor fathers are "natural" caregivers, but that it is a learned behavior for both (Lamb, 1987). Mothers appear to be more competent after the first year and only because they generally spend more time with their infants during the first year of life. Given that increasing numbers of fathers (gay and non-gay alike) are assuming the role of primary caregiver, researchers have a vast untapped field of work that holds the promise of changing the way parenting is conceptualized in this culture.

Future research with similar populations will also likely be faced with addressing shifts in the current political climate and how this relates to the overall psychological health of these families. As the political climate becomes more influenced by extreme and fanatically conservative religious views, it is possible that the health of these families might be compromised. In addition, more and more states are moving not only to restrict the definition of marriage to exclude gays and lesbians, but also to deny adoption to gays and lesbians. One result will be to restrict these families to smaller geographic locales. Another result will be to deny children awaiting adoption the possibility of loving parents and a loving home.

A follow-up study with the children of the current sample would provide valuable insight into the lives of a new generation of children in our society. No study to date has examined adopted children who were raised by two fathers in a loving, committed, and proudly visible partnership. In addition, a longitudinal study of the same sample would 
elucidate developmental changes in these families as the children move through the education system and as the children age and approach adolescence. Follow-up examination of this population would also provide valuable information on how these families adapt to the ongoing process of adoption.

Future research in the area will also inform clinical practice, especially in the area of family therapy. As clinicians working with gay and lesbian headed families, we cannot assume that existing theories of family intervention translate directly to work with this population. Clinicians and researchers must examine the unique characteristics of these families as well as the multitude of contextual factors influencing these families. For example, until all gay and lesbian parents can live without the fear of social disapproval from a society that questions their right or ability to parent and until gay and lesbian relationships are given the same equal legal and social standing as heterosexual unions, these families will likely continue to need additional systems of support. In addition, we have much to learn about the intersection of race, gender, and sexual orientation and the contribution of families who encompass all of these characteristics. While the challenges to these families may be more obvious, research also needs to focus on the particular strengths of these families and their ability to thrive.

Research in this area must not be the sole domain of gay and lesbian researchers. Findings from future research with primary caregiving fathers (PCGF's) hold the promise of better identifying what factors contribute not only to being a "good" father or a "good" mother, but more importantly, to being a "good" parent. This knowledge can inform legislation and social policy related to parenting, adoption, and child welfare.

\section{Limitations of the Current Study}

All research has some limitations both in the methods used and in the applicability of the results. Such limitations are inherent in the research that we conduct 
with human subjects. While precautions were taken and guidelines followed, findings from the current study are, however, limited by some contextual factors.

The sample in the current study was predominantly Caucasian, although four of the couples were of mixed ethnicity. It is possible that ethnic minority couples will report additional stressors on their families as they deal with the dual minority status of their ethnicity and their sexual orientation. In fact, Mallon (2004) reports that Black and Latino gay fathers are more likely to be involved in kinship care (raising the children of siblings or other family members). These families are sure to have a different story to tell than the families in the current study. In addition, all of the men in the current study reported incomes of $\$ 75,000$ to $\$ 100,000$ or higher. The homogeneity in socio-economic status of the sample is likely a result of the fact that participant recruitment was confined to the San Francisco Bay Area; a city with an extremely high cost of living. Research with samples from different geographic regions may yield different results. Finally, many of the participants knew one another. While this is a by-product of the snowball method of sampling, it may also have promoted increased homogeneity of findings from the current study.

California is one of only eight states (along with Connecticut, Illinois, Massachusetts, New Jersey, New York, Pennsylvania, and Vermont) that offers secondparent adoptions to same-sex couples (Human Rights Campaign, 2004). Second-parent adoption provides two legal parents for the child and grants the adoptive parents the same rights as biological parents. It is likely that same-sex parents who reside in states that prohibit second-parent adoptions will identify different or additional stressors and employ different methods of dealing with those stressors.

It is also possible that the structure of the interview format caused some important information to be missed. Due to time and economic constraints, the study did not allow 
for face-to-face follow up interviews. In addition, it might have been beneficial to interview each couple separately after the initial couple interview. This would allow individual members of each dyad the opportunity to discuss issues they might not feel comfortable discussing in the presence of their partners.

Finally, another possible limitation was the presence of the children in the majority of the interviews. While this also allowed the researcher the opportunity to witness interactions between the fathers and their children, it was, at times, distracting for the fathers. Therefore, fathers might not have been as engaged in the interview process when they were attending to the needs of their children.

Despite the stated limitations, the current study provides interesting insight into a new social phenomenon, that of gay adoptive fathers. As part of the first wave of grounded theory research in this area, this study, as well as the others mentioned, provides important theoretical groundwork to inform future research on this topic. As social mores and attitudes about homosexuality and homosexual parents change, there are likely to be many more same-sex parents choosing to adopt. These families will continue to provide researchers with important opportunities to study how families cope with adversity and face societal challenges. 


\section{Appendix A}

\section{Interview Questions for Couples}

1. Please tell me about your decision to adopt and what factors motivated you to do so. Tell me about the planning process that led up to the adoption.

2. If one of you is the adoptive father (as opposed to both) how was this decision reached?

3. What role, if any, did the birth parent(s) play in the adoption? Do you currently maintain contact with birth parent(s)? (How is this negotiated?)

4. Tell me about your experiences as gay fathers. What have been the benefits? Have there been disadvantages?

5. What effect has adoption/having children had on your relationship with one another?

6. Could you please speak about your experiences with support and discrimination from society (as gay fathers) and specifically from the heterosexual parenting community?

7. Now, could you please speak about your experiences with support and discrimination from the gay community and specifically from the same-sex parenting community?

8. To whom or to what (agencies, groups, etc.) do you typically turn for support?

9. How have your lives as gay men changed since you became fathers?

10. What effect has becoming a father had on your identity as a man? As a gay man?

11. Could you please tell me about the structure of a typical day in your lives?

12. How do you decide who does what in terms of child care, housework, etc? Are these duties typically split 50/50 or does one partner take responsibility for certain tasks?

13. If your child is of school-age, what have been your experiences with schools, day care, or other educational institutions?

14. Please tell me about your relationship with your own parents. Has becoming a father had an impact on this relationship? 
15. Please tell me about your "chosen family" or those to whom you have close emotional ties and to whom you may turn to for support, but that are not necessarily "blood related".

How have these relationships changed since becoming fathers?

What role do these relationships play in your family?

16. How have you discussed the uniqueness of your family (e.g. same-sex parents, issue of adoption, how they were chosen, how your family was formed) with your child(ren)? If you have not yet done so, how do you think you might do this?

17. What role, if any, does religion or spirituality play in your family life?

18. How did you negotiate the legal aspects of creating your family? 


\section{Appendix B}

1. Would each of you please tell me in your own words when you first had the though that you might like to have children.

2. Are both of you listed as the adoptive parents on the birth certificate? If not, who is listed and how did you decide that?

3. What was your relationship with the birth mother prior to the birth and adoption and what is your relationship with her now.

4. Please tell me about your experience with the agency and or attorney you used during the adoption process.

5. Please tell me about your experiences as fathers, both in the larger society and within the "gay community." Negative and positive experiences

6. How have each of your biological families reacted to your adopting a child. Has becoming a father changed your relationship with your family?

7. Has becoming a father changed how your view yourself as a gay man, i.e. has your identity as a gay man changed?

8. Please tell me how your relationship with each other has changed since becoming fathers.

9. To whom do you turn for support?

10. How do you negotiate child-care responsibilities? If one of you stays home, or is the primary caregiver, how was this decided?

11. What have your experiences been with schools or daycare facilities?

12. How do you plan to talk to your child about your family? 


\section{Appendix C}

\section{Brief Questionnaire}

\author{
Participant Number
}

1. Age

2. Ethnicity

3. At what age did you seriously consider having children?

4. What is the highest level of education that you have completed?

5. In what range does your total household income fall? (Circle one)

$<\$ 20,000 \quad \$ 20,000-\$ 29,000 \quad \$ 30,000-\$ 39,000 \quad \$ 40,000-\$ 49,000$

$$
\$ 50,000-\$ 75,000 \quad \$ 75,000-\$ 100,000 \quad>\$ 100,000
$$

6. Do you rent or own your home?

7. How many children do you have?

8. What are their ages?

9. Do(es) your child(ren) participate in day-care or childcare outside the home?

10. If yes, how many hours do they participate in childcare on average per week? 


\section{Appendix D}

\section{Making Room for Daddies: Male Couples and Their Adopted Children}

You are invited to participate in a study of gay men and their adopted children. My name is Greg Wells and I am a graduate student at the University of Texas at Austin, Department of Educational Psychology. This study is part of the research necessary to complete requirements related to my dissertation. I hope to discover factors common to the families gay male couples create through adoption. You were selected as a possible participant in this study because you and your partner recently adopted a child. You and your partner will be one of about 10 couples chosen to participate in this study.

If you decide to participate, I will visit you in your home for a face-to-face interview that will take approximately one to two hours. I will ask questions related to your decision to adopt and your experiences as a family. Risks related to your participation are minimal. During the interview process you may recall events and/or feelings that are possibly emotional or distressing. You may also benefit from participation in the study by gaining insight to your own experiences. You will also be contributing to the field of psychology by providing information on the experience of gay male adoption.

Any information that is obtained in connection with this study and that can be identified with you will remain confidential and will be disclosed only with your permission. Interviews will be taped, but will not contain any identifying information (such as names and addresses) about the interviewee.

Your decision whether or not to participate will not affect your future relations with The University of Texas at Austin or with the referring person or agency. You are making a decision whether or not to participate. If you decide to participate, you may withdraw at any time.

If you have questions, please ask me. If you have any additional questions later, I, Greg Wells, will be happy to answer them. I can be contacted at P.O. Box 53374 New Orleans, LA 70153 (504) 231-4041 or at nolaguy@ cox.net. You may also contact my dissertation supervisor, Deborah Tharinger, Ph.D., University of Texas at Austin, SZB 254, Austin, TX 78712 (512) 471-4407 or dtharinger@mail.utexas.edu.

You may keep a copy of this form.

Participant Signature

Participant Signature

Investigator Signature

114 


\section{References}

Achtenberg, R. (1990). Preserving and protecting the families of lesbians and gay men. San Francisco: National Center for Lesbian Rights.

Baruch, G.K., \& Barnett, R.C. (1986). Consequences of fathers' participation in family work: Parents' role strain and well-being. Journal of Personality and Social Psychology, 51, 983-992.

Bigner, J.J. \& Jacobsen, R.B. (1989). Parenting behaviors of homosexual and heterosexual fathers. Journal of Homosexuality, 18 (1-2), 173-186.

Boyd-Franklin, N. (1993). Race, class, and poverty. In F. Walsh (Ed.), Normal Family Processes, $2^{\text {nd }}$ ed. New York: Guilford Press.

Bozett, F.W. (1980). Gay fathers: How and why they disclose their homosexuality to their children. Family Relations, 29, 173-179.

Bozett, F.W. (1988). Gay fatherhood. In P. Bronstein \& Pape Cowan, C. (Eds.), Fatherhood today: Men's changing role in the family. New York: John Wiley \& Sons.

Bozett, F.W. (1989). Gay fathers: A review of the literature. In F.W. Bozett, (Ed.), Homosexuality and the family (pp. 137-162). New York: Harrington Press.

Brinamen, C.F. (2000). On becoming fathers: Issues facing gay men choosing to parent (Doctoral dissertation, California School of Professional Psychology, 2000). Dissertation Abstracts International, 61 (05), 2794. (UMI No. 9973822)

Brodzinsky, D.M. (1987). Adjustment to adoption: A psychosocial perspective. Clinical Psychology Review, 7, 25-47.

Bull, C. (2002, March 19). Rx for gay parenting. The Advocate, 720, 20.

Cabrera, N.J., Tamis-LeMonda, C.S., Bradley, R.H., Hofferth, S., \& Lamb, M.E. (2000). Fatherhood in the twenty-first century. Child Development, 71(1), 127-136.

Cass, V.C. (1984). Homosexual identity formation: testing a theoretical model. Journal of Sex Research, 20, 143-167.

Clark, D. (1977). Loving someone gay. Millbrae, CA: Celestial Arts.

Cohen, N.J., Coyne, J.C., \& Duvall, J.D. (1996). Parents' sense of "entitlement" in adoptive and nonadoptive families. Family Process, 35, 441-456. 
Cowan, C.P., \& Cowan, P. A. (1987). Men's involvement in parenthood: Identifying the antecedents and understanding the barriers. In P. Berman \& F.A. Pedersen (Eds.), Men: transitions to parenthood. Hillsdale, NJ: Erlbaum.

Cowan, P.A. (1988). Becoming a father. In P. Bronstein \& C.P. Cowan (Eds.), Fatherhood today: Men's changing role in the family. New York: WileyInterscience.

Daniels, P. \& Weingarten, K. (1982). Sooner or later: The timing of parenthood in adult lives. New York: Norton.

Erikson, E.H. (1982). The life cycle completed: a review. New York: Norton.

Erikson, E.H. (1963). Childhood and society (2 ${ }^{\text {nd }}$ ed.). New York: W.W. Norton and Co.

Flaks, D.K., Ficher, I., Masterpasqua, F., \& Joseph, G. (1995). Lesbians choosing motherhood: A comparative study of lesbians and heterosexual parents and their children. Developmental Psychology, 31, 105-114.

Gilbert, L.A. (1988). Sharing it all : the rewards and struggles of two-career families. New York: Plenum.

Greenan, D.E., \& Tunnell, G. (2003). Couple therapy with gay men. New York, NY: Guilford Press.

Grotevant, H.D., \& McRoy, R.G. (1998). Openness in adoption: Exploring family connections. Newbury Park, CA: Sage.

Grotevant, H.D. \& Kohler, J.K. (1999). Adoptive Families. In M.E. Lamb (Ed.), Parenting and child development in "nontraditional" families. New Jersey: Lawrence Erlbaum Associates, Inc.

Hanson, S. (1985). Single fathers with custody: A synthesis of the literature. In B. Schlesinger, (Ed.), The one-parent family in the 1980's. Toronto: University of Toronto Press.

Harrison, L. A., \& Lynch, A.B. (2005). Social role theory and the perceived gender role orientation of athletes. Sex Roles: A Journal of Research, 52, 227-236.

Harry, J. (1990). Gay male and lesbian relationships. In E.D. Macklin and R.H. Rubin (Eds.), Contemporary families and alternative lifestyles: Handbook on research and theory (pp. 216-234). Newbury Park, CA: Sage.

Hobbs, D. (1965). Parenthood as a crisis: A third study. Journal of Marriage and the Family, 27, 367-372. 
Human Rights Campaign Foundation Report. (April 13, 2004). The cost of marriage inequality to children and their same-sex parents. Retrieved October 27, 2004, from http://www.hrc.org/Content/ContentGroups/Publications1/kids_doc_final.pdf

Hwang, C.P., Elden, G., \& Frannson, A. (1984). Employers' and co-workers' attitudes toward father taking parental leave. Sweden: University of Goteborg, Department of Psychology, Report 31.

Kirk, H.D. (1981). Adoptive kinship: A modern institution in need of reforms. Toronto, Canada: Butterworth.

Laird, J. (1993). Lesbian and gay families. In F. Walsh (Ed.), Normal Family Processes, $2^{\text {nd }}$ ed. New York: Guilford Press.

Lamb, M.E. (1986). The changing roles of fathers. In M.E. Lamb (Ed), The father's role: Applied perspectives (pp. 3-27). New York: Wiley-Interscience.

Lamb, M.E. (1987). Introduction: The emergent American father. In M.E. Lamb (Ed.), The father's role: Cross-cultural perspectives (pp. 3-25). Hillsdale, NJ: Lawrence Erlbaum Associates.

Lamb, M.E. (1997). The development of father-infant relationships. In M.E. Lamb (Ed.), The role of the father in child development (pp. 105-120). New York: Wiley.

Lamb, M.E., Pleck, J.H., Charnov, E.L., \& Levine, J.A. (1987). A biosocial perspective on paternal behavior and involvement. In J.B. Lancaster, J. Altman, A. Rossi, \& L.R. Sherrod (Eds.), Parenting across the lifespan: Biosocial perspectives (pp. 1142). New York: Academic.

Lasser, J., and Tharinger, D. (1997) Sexual Minority Youth. In G.G. Bear, K.M. Minke, \& A. Thomas (Eds.), Children's Needs II: Development, Problems, and Alternatives. Bethesda, Maryland: National Association of School Psychologists.

Lein, L. (1979). Male participation in home life: Impact of social supports and breadwinner responsibility on the allocation of tasks. Family Coordinator, 28, 489-495.

LeMasters, E. (1957). Parenthood as crisis. Marriage and Family Living, 19, 352-355.

Lichtanski, K. (2004). A comparison of adoptive gay and adoptive heterosexual fathers: Differences in their perception of parenting abilities, level of parental stress, style of parenting, and available social support. Dissertation Abstracts International, 65 (05), 2635. (UMI No. 3132743) 
Lutwin, D.R. \& Siperstein, G.N. (1985). Househusband fathers. In S.M.H. Hanson \& F.W. Bozett (Eds.), Dimensions of fatherhood (pp. 269-287). California: Sage.

Mallon, G.P. (2004). Gay men choosing parenthood. New York: Columbia University Press.

Martin, A. (1993). The lesbian and gay parenting handbook: Creating and raising our families. New York: HarperCollins.

McHale, S.M. \& Huston, T.L. (1984). Men and women as parents: Sex role orientations, employment, and parental roles with infants. Child Development, 55, 1349-1361.

McPherson, D. (1993). Gay parenting couples: Parenting arrangements, arrangement satisfaction, and relationship satisfaction. Unpublished doctoral dissertation, Pacific Graduate School of Psychology at Palo Alto, CA.

Melina, L.R. (1998). Raising adopted children. New York: Quill.

Miller, B. (1979, October). Gay fathers and their children. The Family Coordinator, 28, 544-551.

Miller, B. \& Sollie, D. (1980). Normal stresses during the transition to parenthood. Family Relations, 29, 459-465.

Okun, B.F. (1996). Understanding diverse families: What practitioners need to know. New York: Guilford Press.

Osofsky, H. (1982). Expectant and new fatherhood as a developmental crisis. Bulletin of the Menninger Clinic, 46, 209-230.

Oswald, R.M. (2002). Resilience within the family networks of lesbians and gay men: Intentionality and redefinition. Journal of Marriage and Family Therapy, 64, 374383.

Park, R.D., \& Swain, D. (1976). The father's role in infancy: A reeducation. Family Coordinator, 24(4), 467-468.

Patterson, C.J. (1992). Children of lesbian and gay parents. Child Development, 63, 1025-1042.

Patterson, C.J. (1995). Families of the lesbian baby boom: Parents' division of labor and children's adjustment. Developmental Psychology, 31, 115-123.

Patterson, C.J. \& Chan, R.W. (1996). Gay fathers. In M.E. Lamb (Ed.), The role of the father in child development $\left(3^{\text {rd }}\right.$ ed., pp. 245-260). New York: John Wiley \& Sons. 
Patterson, C.J. \& Chan, R.W. (1999). Families headed by lesbian and gay parents. In M.E. Lamb (Ed.), Parenting and child development in "nontraditional" families. New Jersey: Lawrence Erlbaum Associates, Inc.

Pleck, J.H. (1987). American fathering in historical perspective. In M.S. Kimmel (Ed.), Changing men: New directions in research on men and masculinity. Newbury Park, CA: Sage.

Pleck, J.H. (1997). Paternal involvement: Levels, sources, and consequences. In M.E. Lamb (Ed.), The role of the father in child development (pp. 66-103). New York: Wiley.

Pleck, J.H., Lamb, M.E., \& Levine, J.A. (1986). Epilogue: Facilitating future change in men's family roles. In R.A. Lewis \& M. Sussman (Eds.), Men's changing roles in the family (pp. 11-16). New York: Haworth.

Pruett, K.D. (1989). The nurturing male: a longitudinal study of primary nurturing fathers. In S. Cath, A. Gurwitt, \& L. Gunsberg (Eds.), Fathers and their families (pp. 389-405). Hillsdale, NJ: Erlbaum.

Radin, N. (1988). Primary caregiving fathers of long duration. In P. Bronstein \& C.P. Cowan (Eds.), Fatherhood today (pp. 127-143). New York: Wiley.

Radin, N. (1994). Primary-caregiving in fathers in intact families. In A.E. Gottfried \& A.W. Gottfried (Eds.), Redefining families: Implications for children's development. New York: Plenum Press.

Radin, N., \& Russell, G. (1983). The effect of fathers on child development: A consideration of traditional families and those with highly involved fathers. In M.E. Lamb \& A. Sagi (Eds.), Fatherhood and social policy (pp. 191-218). Hillsdale, NJ: Erlbaum.

Rapoport, R., \& Rapoport, R.N. (1976). Dual-career families reexamined. New york: Harper and Row.

Reitz, M. \& Watson, K.W. (1992). Adoption and the family system. New York: Guilford.

Ricketts, W. (1991). Lesbians and gay men as foster parents. Portland, ME: University of Southern Main, National Child Welfare Resource Center.

Roopnarine, J.L. \& Miller, B.C. (1985). Transitions to fatherhood. In S.M.H. Hanson \& F.W. Bozett (Eds.), Dimensions of fatherhood (pp. 49-63). California: Sage.

Rothblum, E. \& Cole, E. (Eds.). (1989). Loving boldly: Issues facing lesbians. New York: Harrington Park. 
Rubin, H.J. \& Rubin, I.S. (1995). Qualitative interviewing: The art of hearing data. Newbury Park, CA: Sage.

Russell, C. (1974). Transition to parenthood: Problems and gratifications. Journal of Marriage and the Family, 36, 294-301.

Russell, G. (1986). Primary caretakers and role sharing fathers. In M.E. Lamb (Ed.), The father's role: Applied perspectives (pp. 29-60). New York: Wiley.

Russell, G., \& Radin, N. (1983). Increased paternal participation: The father's perspective. In M.E. Lamb \& A. Sagi (Eds.), Fatherhood and family policy (pp. 139-165). Hillsdale, NJ: Erlbaum.

Sbordone, A.J. (1993). Gay men choosing fatherhood. Unpublished doctoral dissertation, City University of New York, New York.

Schacher, S. (2000). Fathering experiences of the "new" gay fathers: A qualitative research study. Unpublished doctoral dissertation, Yeshiva University, New York.

Silverstein, L. (1996). Fathering is a feminist issue. Psychology of Women Quarterly, 20, 3-37.

Silverstein, L.B. (2002). Fathers and families. In J.P. McHale \& W.S. Grolnick (Eds.). Retrospect and prospect in the psychological study of families (pp. 35-64). Mahwah, NJ: Lawrence Erlbaum Associates.

Skeen, P. \& Robinson, B. (1984). Family background of gay fathers: A descriptive study. Psychological Reports, 54, 999-1005.

Smith, D.M. \& Gates, G.J. (2001). Gay and lesbian families in the United Sates: Samesex unmarried partner households. A preliminary analysis of 2000 United States Census data. Washington, D.C: Human Rights Campaign.

Stacey, J. (1998). Gay and lesbian families: Queer like us. In Mason, M.A., Skolnick, A., Sugarman, S.D. (Eds.) All our families: New policies for a new century. Oxford University Press.

Stacey, J. \& Biblarz, T.J. (2001). How does sexual orientation of parents matter? American Sociological Review, 66 (2), 159-183.

Strauss, A.L. \& Corbin, J. (1998). The basics of qualitative research: Techniques and procedures for developing grounded theory. $2^{\text {nd }}$ edition. Thousand Oaks, CA: Sage. 
Troiden, R.R. (1989). The formation of homosexual identities. Journal of Homosexuality, 17, 43-73.

Waterman, A.S. (1992). Psychosocial development in adulthood: a 22-year sequential study. Journal of Personality and Social Psychology, 63, 260-272.

Wood, W., \& Eagly, A.H. (2002). A cross-cultural analysis of the behavior of women and men: Implications for the origins of sex differences. Psychological Bulletin, $128,699-727$.

Wyers, N.L. (1984). Lesbian and gay spouses and parents: Homosexuality in the family. Portland School of Social Work: Portland State University. 


\section{Vita}

Gregory Charles Wells was born in Houston, Texas on March 16, 1970, the son of Donald and Carole Wells. After completing his work at Galena Park High School in 1987, he attended San Jacinto Junior College and Austin Community College before entering the University of Texas at Austin. He received the degree of Bachelor of Arts from the University of Texas in 1993 and the degree of Master of Arts in 1999. In August, 2005 he graduated from the University of Texas.

Permanent address: $\quad$ PO Box 53374, New Orleans, LA 70153

This dissertation was typed by the author. 